\title{
Chemical ionization of clusters formed from sulfuric acid and dimethylamine or diamines
}

\author{
Coty N. Jen ${ }^{1, a}$, Jun Zhao ${ }^{1, b}$, Peter H. McMurry ${ }^{1}$, and David R. Hanson ${ }^{2}$ \\ ${ }^{1}$ Department of Mechanical Engineering, University of Minnesota, Twin Cities, 111 Church St. SE, \\ Minneapolis, MN 55455, USA \\ ${ }^{2}$ Department of Chemistry, Augsburg College, 2211 Riverside Ave., Minneapolis, MN 55454, USA \\ ${ }^{a}$ now at: Department of Environmental Science, Policy, and Management, University of California, Berkeley, \\ Hilgard Hall, Berkeley, CA 94720, USA \\ b now at: Institute of Earth Climate and Environment System, Sun Yat-sen University, 135 West Xingang Road, \\ 510275 Guangzhou, China
}

Correspondence to: Coty N. Jen (jenco@berkeley.edu)

Received: 9 June 2016 - Published in Atmos. Chem. Phys. Discuss.: 1 July 2016

Revised: 13 September 2016 - Accepted: 21 September 2016 - Published: 7 October 2016

\begin{abstract}
Chemical ionization (CI) mass spectrometers are used to study atmospheric nucleation by detecting clusters produced by reactions of sulfuric acid and various basic gases. These instruments typically use nitrate to deprotonate and thus chemically ionize the clusters. In this study, we compare cluster concentrations measured using either nitrate or acetate. Clusters were formed in a flow reactor from vapors of sulfuric acid and dimethylamine, ethylene diamine, tetramethylethylene diamine, or butanediamine (also known as putrescine). These comparisons show that nitrate is unable to chemically ionize clusters with high base content. In addition, we vary the ion-molecule reaction time to probe ion processes which include proton-transfer, ion-molecule clustering, and decomposition of ions. Ion decomposition upon deprotonation by acetate/nitrate was observed. More studies are needed to quantify to what extent ion decomposition affects observed cluster content and concentrations, especially those chemically ionized with acetate since it deprotonates more types of clusters than nitrate.

Model calculations of the neutral and ion cluster formation pathways are also presented to better identify the cluster types that are not efficiently deprotonated by nitrate. Comparison of model and measured clusters indicate that sulfuric acid dimers with two diamines and sulfuric acid trimers with two or more base molecules are not efficiently chemical ionized by nitrate. We conclude that acetate $\mathrm{CI}$ provides bet-
\end{abstract}

ter information on cluster abundancies and their base content than nitrate $\mathrm{CI}$.

\section{Introduction}

Atmospheric nucleation is an important source of global atmospheric particles (IPCC, 2014). In the atmospheric boundary layer, sulfuric acid often participates in nucleation (Weber et al., 1996; Kuang et al., 2008; Kulmala et al., 2004; Riipinen et al., 2007) by reacting with other trace compounds to produce stable, electrically neutral molecular clusters; these compounds include ammonia (Kirkby et al., 2011; Coffman and Hegg, 1995; Ball et al., 1999), amines (Almeida et al., 2013; Zhao et al., 2011; Glasoe et al., 2015), water (Leopold, 2011), and oxidized organics (Schobesberger et al., 2013). The primary instruments used for detecting freshly nucleated, sulfuric-acid-containing clusters are atmospheric-pressure chemical ionization mass spectrometers (CIMS) such as the Cluster CIMS (Zhao et al., 2010; Chen et al., 2012) and the chemical ionization (CI) atmospheric-pressure interface-time-of-flight mass spectrometer (CI-APi-ToF; Jokinen et al., 2012). Both mass spectrometers use nitrate to chemically ionize neutral sulfuric acid clusters. Depending upon conditions, $\mathrm{NO}_{3}^{-}$core ions generally have one or more $\mathrm{HNO}_{3}$ and possibly several $\mathrm{H}_{2} \mathrm{O}$ ligands The signal ratio of the ion cluster to the reagent ion 
translates to the neutral cluster concentration (Berresheim et al., 2000; Hanson and Eisele, 2002; Eisele and Hanson, 2000).

The amounts and types of ions detected by the mass spectrometer are affected by four key processes: the abundance of neutral clusters, their ability to be chemically ionized, product ion decomposition, and clustering reactions of the product ions (ion-induced clustering, IIC). The first process, neutral cluster formation, follows a sequence of acid-base reactions (Chen et al., 2012; Jen et al., 2014; Almeida et al., 2013; McGrath et al., 2012) whereby sulfuric acid vapor and its subsequent clusters react with basic molecules to produce clusters that are more stable than aqueous sulfuric acid clusters. The concentration of a specific cluster type depends on its stability (i.e., evaporation rates of the neutral cluster) and the concentrations of precursor vapors (i.e., the formation rate).

Neutral clusters then need to be ionized to be detected with a mass spectrometer. In most prior work, this has been accomplished by chemical ionization with the nitrate ion whereby the neutral clusters are exposed to nitrate for a set amount of time known as the chemical ionization reaction time (or ion-molecule reaction time). CI can be conceptualized as another acid-base reaction where an acid (sulfuric acid) donates a proton to the basic reagent ion (nitrate, the conjugate base of nitric acid). To illustrate, the CI reaction of an aminated sulfuric acid dimer, $\left(\mathrm{H}_{2} \mathrm{SO}_{4}\right)_{2} \cdot \mathrm{DMA}$, is shown in Reaction (R1).

$$
\begin{aligned}
& \left(\mathrm{H}_{2} \mathrm{SO}_{4}\right)_{2} \cdot \mathrm{DMA} \cdot\left(\mathrm{H}_{2} \mathrm{O}\right)_{x}+\mathrm{HNO}_{3} \cdot \mathrm{NO}_{3}^{-} \stackrel{k_{2}}{\rightarrow} \\
& \mathrm{HSO}_{4}^{-} \cdot \mathrm{H}_{2} \mathrm{SO}_{4} \cdot \mathrm{DMA}+2 \mathrm{HNO}_{3}+x\left(\mathrm{H}_{2} \mathrm{O}\right)
\end{aligned}
$$

This dimer of sulfuric acid contains a dimethylamine (DMA) molecule and $x$ water molecules. At room temperature, water molecules evaporate upon ionization or entering the vacuum region and are assumed to not significantly affect chemical ionization rates. The forward rate constant, $k_{2}$, is assumed to be the collisional rate coefficient of $1.9 \times 10^{-9} \mathrm{~cm}^{3} \mathrm{~s}^{-1}$ (Su and Bowers, 1973), while the reverse rate constant is 0 .

Reaction (R1) can be extended to CI reactions for larger neutral clusters of sulfuric acid, with the assumption that every collision between nitrate and a sulfuric acid cluster results in an ionized cluster. However, Hanson and Eisele (2002) presented evidence that some clusters of sulfuric acid and ammonia were not amenable to ionization by $\left(\mathrm{HNO}_{3}\right)_{1-2} \cdot \mathrm{NO}_{3}^{-}$. Acetate $\mathrm{CI}$ has been used previously to detect organic acids less acidic than sulfuric acid in the atmosphere, providing evidence that its higher proton affinity could chemically ionize more basic clusters (Veres et al., 2008). Subsequently, Jen et al. (2015) showed that CI with $\left(\mathrm{HNO}_{3}\right)_{1-2} \cdot \mathrm{NO}_{3}^{-}$leads to significantly lower neutral concentrations of clusters with three or more sulfuric acid molecules and varying numbers of DMA molecules compared to results using acetate reagent ions. Furthermore, neu- tral cluster concentrations detected using acetate CI are in overall better agreement with values measured using a diethylene glycol mobility particle sizer (DEG MPS). As no other experimental conditions changed except the CI reagent ion, we hypothesized that nitrate's proton affinity, which is lower than that of acetate, renders it less able to chemically ionize clusters that contain nearly equal amounts of sulfuric acid and base. Poor $\mathrm{CI}$ efficiency reduces the amount and types of ions detected by the mass spectrometer.

After neutral clusters are ionized, the resulting ion may decompose. Experimental studies have shown ion decomposition in the ammonia-sulfuric acid system at $275 \mathrm{~K}$ (Hanson and Eisele, 2002), and computational chemistry studies present evaporation rates of ion clusters of sulfuric acid with various bases on the order of the CI reaction time used here (Kurtén et al., 2011; Lovejoy and Curtius, 2001; Ortega et al., 2014). For example, these studies predict an evaporation rate, $E_{\mathrm{d}}$ (Reaction R2), of DMA from a sulfuric acid dimer ion with one DMA molecule of $\sim 100 \mathrm{~s}^{-1}$ at $298 \mathrm{~K}$ (Ortega et al., 2014).

$$
\mathrm{HSO}_{4}^{-} \cdot \mathrm{H}_{2} \mathrm{SO}_{4} \cdot \mathrm{DMA} \stackrel{E_{\mathrm{d}}}{\longrightarrow} \mathrm{HSO}_{4}^{-} \cdot \mathrm{H}_{2} \mathrm{SO}_{4}+\mathrm{DMA}
$$

Experimental observations at room temperature have never seen the aminated sulfuric acid dimer ion, even at CI reaction times as short as a few milliseconds. Thus, the decomposition rate is likely even faster than the computed value of $\sim 100 \mathrm{~s}^{-1}$ at $298 \mathrm{~K}$ (Ortega et al., 2014).

Ion clusters can also be produced by ion-induced clustering (IIC) whereby the bisulfate ion $\left(\mathrm{HSO}_{4}^{-}\right)$, formed by $\mathrm{CI}$ of sulfuric acid monomer, further reacts with $\mathrm{H}_{2} \mathrm{SO}_{4}$ (with ligands) and larger clusters. Charged clusters can also cluster with neutrals to form larger ion clusters. The signal due to these IIC products must be subtracted from the observed signals to determine neutral cluster concentrations. Specifically, the sulfuric dimer ion can be formed via the IIC pathway given in Reaction (R3), with ligands not shown.

$$
\mathrm{HSO}_{4}^{-}+\mathrm{H}_{2} \mathrm{SO}_{4} \stackrel{k_{21}}{\longrightarrow} \mathrm{HSO}_{4}^{-} \cdot \mathrm{H}_{2} \mathrm{SO}_{4}
$$

The forward rate constant, $k_{21}$, is the collisional rate constant of $2 \times 10^{-9} \mathrm{~cm}^{3} \mathrm{~s}^{-1}$ because this reaction involves switching ligands between the two clusters. Both reactants also contain water, nitrate, and/or base ligands that detach during measurement. The IIC-produced dimer signal interferes with the CI-detected neutral dimer but can be calculated from measured sulfuric acid vapor concentrations and CI reaction times (Chen et al., 2012; Hanson and Eisele, 2002).

IIC can also produce larger clusters, but in general its contribution is less than for the dimer, even if all rates are assumed to be collisional. Furthermore, bisulfate may not efficiently cluster with chemically neutralized sulfate salt clusters formed by reactions of sulfuric acid and basic compounds. If so, assuming the collisional rate constant for all 
IIC-type reactions would lead to an overcorrection of the neutral cluster concentrations.

Measured CIMS signals reflect the combined influences of all these processes, with each occurring on timescales that depend on the chemistry, experimental parameters, and techniques. Assuming a process is either dominant or negligible can lead to large errors in reported neutral cluster compositions and concentrations. Here, neutral cluster formation, chemical ionization, IIC, and ion decomposition are examined experimentally and theoretically to determine the influence of each process on the abundance of ion clusters composed of sulfuric acid and various bases. These bases include DMA, ethylene diamine (EDA), trimethylethylene diamine (TMEDA), and butanediamine (also known as putrescine, Put). The diamines, recently implicated in atmospheric nucleation, react with sulfuric acid vapors to very effectively produce particles compared to monoamines (Jen et al., 2016). We present observations that (1) show a clear difference between acetate and nitrate CI for all clusters larger than the sulfuric acid dimer with any of the bases, (2) provide evidence of ion decomposition, and (3) identify specific bases that influence the detectability of the dimer neutral clusters. Also presented are modeling results that help elucidate specific processes that influence measurement: neutral cluster formation pathways, cluster types that do not undergo nitrate $\mathrm{CI}$, and clusters that are formed by IIC.

\section{Method}

Sulfuric acid clusters containing either DMA, EDA, TMEDA, or Put were produced in a flow reactor that allows for highly repeatable observations (see Jen et al., 2014; Glasoe et al., 2015). Glasoe et al. (2015) showed that the system has a high cleanliness level: 1 ppqv level or below for amines. Each amine was injected into the flow reactor at a point to yield $\sim 3$ s reaction time between the amine and sulfuric acid (see Jen et al., 2014, for a schematic). The initial sulfuric acid concentration $\left(\left[\mathrm{A}_{1}\right]_{o}\right)$ before reaction with basic gas was controlled at specified concentrations. The base concentration, [B], was measured by the Cluster CIMS in positive ion mode (see the Supplement of Jen et al., 2014, for further details) and confirmed with calculated concentrations (Zollner et al., 2012; Freshour et al., 2014). The dilute amines were produced by passing clean nitrogen gas over either a permeation tube (for DMA and EDA) or a liquid reservoir (TMEDA and Put) and further diluted in a process described in Zollner et al. (2012). The temperature of the flow reactor was held constant throughout an experiment but varied day-to-day from 296 to $303 \mathrm{~K}$ to match room temperature. This was done to minimize thermal convection, which induces swirling near the Cluster CIMS sampling region. The relative humidity was maintained at $\sim 30 \%$, and measurements were done at ambient pressure $(\sim 0.97 \mathrm{~atm})$. The total reactor $\mathrm{N}_{2}$ flow rate was $4.0 \mathrm{~L} \mathrm{~min}^{-1}$ at standard conditions of $273 \mathrm{~K}$ and $1 \mathrm{~atm}$.

Two types of experiments were conducted: one set where specific base, base concentration $([\mathrm{B}])$, and $\left[\mathrm{A}_{1}\right]_{o}$ were varied at constant CI reaction time (similar to those in Jen et al., 2014) and the second set where CI reaction time was varied for a subset of reactant conditions (see Hanson and Eisele, 2002; Zhao et al., 2010). The resulting concentrations were measured with the Cluster CIMS using either nitrate or acetate as the CI reagent ion. Nitrate and acetate were produced by passing either nitric acid or acetic anhydride vapor over Po-210 sources. Separate Po-210 sources and gas lines were used for the acetate and nitrate to avoid crosscontamination. The measured reagent ions for nitrate $\mathrm{CI}$ was $\left(\mathrm{HNO}_{3}\right)_{1-2} \cdot \mathrm{NO}_{3}^{-}$, and the reagent ions for acetate $\mathrm{CI}$ were $\mathrm{H}_{2} \mathrm{O} \cdot \mathrm{CH}_{3} \mathrm{CO}_{2}^{-}, \mathrm{CH}_{3} \mathrm{CO}_{2} \mathrm{H} \cdot \mathrm{CH}_{3} \mathrm{CO}_{2}^{-}$, and $\mathrm{CH}_{3} \mathrm{CO}_{2}^{-}$ (in order of abundance). The nitrate dimer and trimer are assumed to chemically ionize at equal rate constants, and the three acetate ions are assumed to chemically ionize in identical manners. The inferred neutral cluster concentrations were calculated from the CI reaction time, measured and extrapolated mass-dependent sensitivity (see the Supplement), and the assumed collisional rate constant between CI ion and sulfuric acid clusters (see Jen et al., 2014, 2015, for a discussion on the data inversion process). The CI reaction time, $t_{\mathrm{CI}}$, was determined from the inlet dimensions and electric field strength inside the sampling region; for this set of experiments, $t_{\mathrm{CI}}$ was fixed at $18 \mathrm{~ms}$ for nitrate and $15 \mathrm{~ms}$ for acetate.

Varying $t_{\mathrm{CI}}$ at fixed $[\mathrm{B}]$ and $\left[\mathrm{A}_{1}\right]_{o}$ was achieved by changing the electric field used to draw ions across the sample flow into the inlet. Similar experiments have been performed with other atmospheric-pressure, CI mass spectrometer inlets (Hanson and Eisele, 2002; Zhao et al., 2010; Chen et al., 2012) with the detailed mathematical relationship between $t_{\mathrm{CI}}$ and ion signal ratios developed more in depth in the following sections and the Supplement.

\section{Acetate vs. nitrate comparison}

Figure 1a and c compare inferred cluster concentrations derived from measured signals (assuming the collisional rate constant, $k_{\mathrm{c}}$, and no ion breakup) using acetate (red squares) and nitrate (black triangles) reagent ions at a constant $\left[\mathrm{A}_{1}\right]_{o} \sim 4 \times 10^{9} \mathrm{~cm}^{-3}$ for two different [DMA]. The grouped points represent clusters that contain an equivalent number of sulfuric acid molecules $\left(\mathrm{N}_{1}\right.$ is the monomer, $\mathrm{N}_{2}$ is the dimer, etc.) but with a different number of DMA molecules (e.g., $\mathrm{A}_{4}^{-} \cdot \mathrm{DMA}_{0-3}$, where $\mathrm{A}$ is sulfuric acid). The number of base molecules in each cluster is given by the grouping bracket. Since the tetramers and pentamers have similar mass ranges, $\mathrm{N}_{4}$ clusters are given as halffilled symbols and $\mathrm{N}_{5}$ clusters as outlined symbols. Note that $\mathrm{N}_{1}$ is detected at different masses between the two reagent 

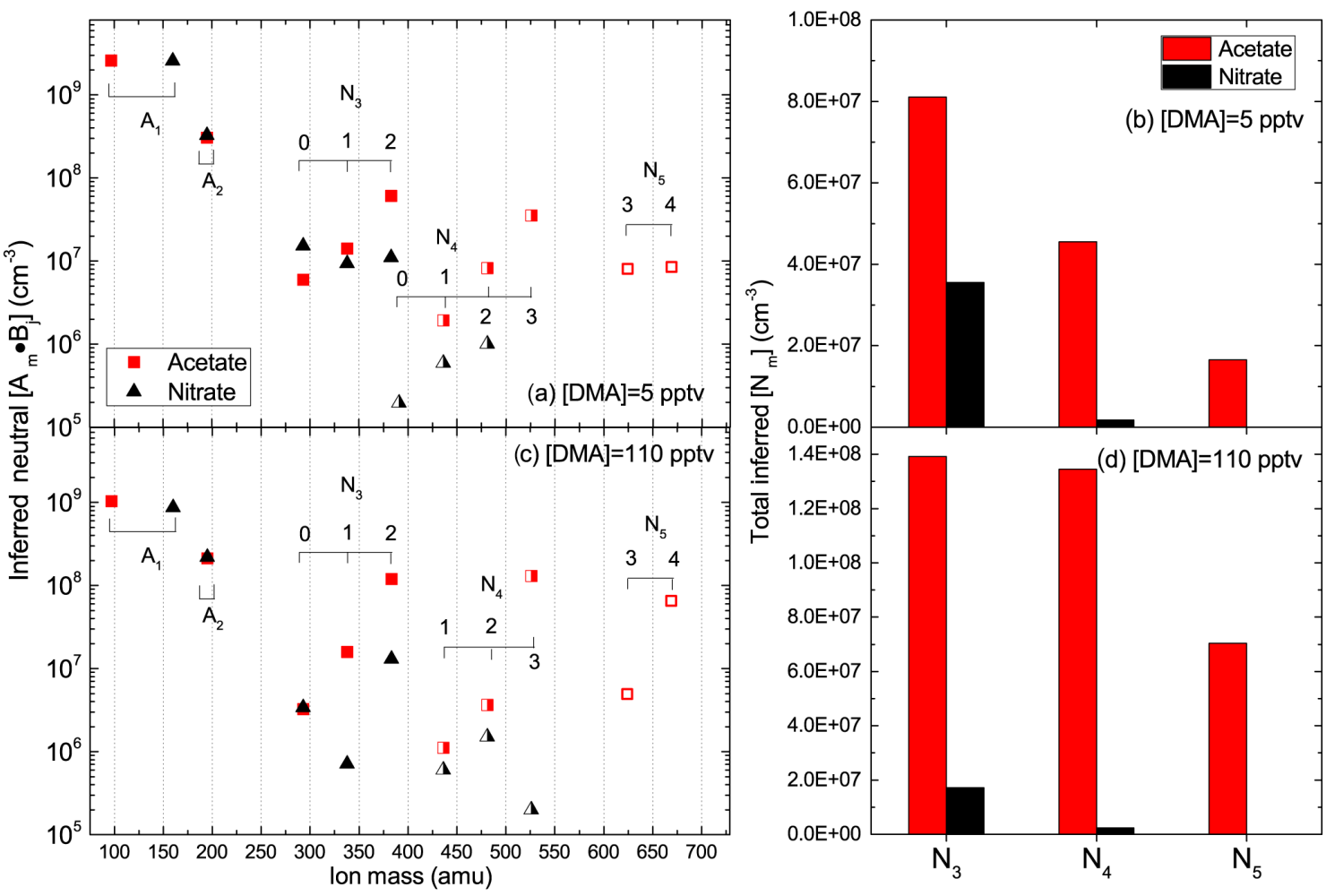

Figure 1. (a, c) Comparison of specific cluster concentrations ([ $\left.\left.\mathrm{A}_{m} \cdot \mathrm{B}_{j}\right]\right)$ using acetate (red squares) and nitrate (black triangles) reagent ions at two different $[\mathrm{DMA}]$ and a constant initial sulfuric acid concentration, $\left[\mathrm{A}_{1}\right]_{o} \sim 4 \times 10^{9} \mathrm{~cm}^{-3}$. Each cluster species is shown at its ion mass. The brackets represent the number of DMA molecules in a cluster with a given number of sulfuric acid. The half-filled symbols show the tetramers, and the outlined symbols are the pentamers. Bar graphs (b) and (d) compare total cluster concentration of a given size ([N $\left.\left.\mathrm{N}_{m}\right]\right)$ between acetate (red) and nitrate (black) for the same $[\mathrm{DMA}]$ and $\left[\mathrm{A}_{1}\right]_{o}$ as (a) and (b), respectively.

ions, with nitrate at $160 \mathrm{amu}=\mathrm{HSO}_{4}^{-} \cdot \mathrm{HNO}_{3}$ and acetate at $97 \mathrm{amu}=\mathrm{HSO}_{4}^{-}$. The total cluster concentrations, $\left[\mathrm{N}_{m}\right]$, compared between the two CI ions are shown in Fig. 1b and $\mathrm{d}$. The notation used here differs slightly from Jen et al. (2014) such that $\left[\mathrm{N}_{m}\right]$ denotes the total concentration for clusters that contain $m$ sulfuric acids molecules (i.e., $\left.\left[\mathrm{N}_{m}\right]=\left[\mathrm{A}_{m}\right]+\left[\mathrm{A}_{m} \cdot \mathrm{B}_{1}\right]+\left[\mathrm{A}_{m} \cdot \mathrm{B}_{2}\right] \ldots\right)$ and $\mathrm{A}_{m} \cdot \mathrm{B}_{j}$ represents a specific cluster type with $m$ sulfuric acid molecules and $j$ basic molecules (B). The measured $\left[\mathrm{N}_{1}\right]$ and $\left[\mathrm{N}_{2}\right]$ obtained using nitrate and acetate are in good agreement for DMA. In the set of bases studied in Jen et al. (2014) (ammonia, methylamine, DMA, and trimethylamine), DMA is the strongest clustering agent, and these results reaffirm the accuracy of previously reported values of $\left[\mathrm{N}_{1}\right]$ and $\left[\mathrm{N}_{2}\right]$ in Jen et al. (2014) at high $\left[\mathrm{A}_{1}\right]_{o}$.

Figures 2, 3, and 4 show the acetate and nitrate comparison for EDA, TMEDA, and Put, respectively. Although nitrate appears to consistently detect less $\left[\mathrm{N}_{1}\right]$ than acetate, the estimated systematic uncertainty of acetate-detected $\left[\mathrm{N}_{1}\right]$ is higher than with nitrate due to higher background signals detected by acetate, sensitivity to the low masses (see the Supplement), and the possible influence of diamines on the ion throughput in the mass spectrometer. Other factors that may influence the detected $\left[\mathrm{N}_{1}\right]$ are discussed in the Supplement. The true acetate $\left[\mathrm{N}_{1}\right]$ could be up to a factor of 5 lower. Therefore, for monomer clusters formed from diamines, it is difficult to conclude that acetate and nitrate lead to significant differences in measured $\left[\mathrm{N}_{1}\right]$.

Unlike the other bases, Put was observed in the monomer using either nitrate or acetate CI (Fig. 4). The presence of $\mathrm{A}_{1}^{-} \cdot$ Put indicates that its binding energy must be higher than monomers containing the other bases. However, this ion still decomposes in roughly the $t_{\mathrm{CI}}=15 \mathrm{~ms}$ as it is $\sim 0.1 \%$ of $\left[\mathrm{N}_{1}\right]$. Elm et al. (2016) have shown that the binding energy of $A_{1} \cdot E D A$ is $-11.1 \mathrm{kcal} \mathrm{mol}^{-1}$ and $A_{1} \cdot$ Put is $-15.4 \mathrm{kcal} \mathrm{mol}^{-1}$, with $A_{1} \cdot$ DMA closely matching $\mathrm{A}_{1} \cdot$ EDA at $-11.38 \mathrm{kcal} \mathrm{mol}^{-1}$ (Nadykto et al., 2014; Bork et al., 2014). The higher neutral binding energies of $\mathrm{A}_{1} \cdot$ Put may translate to stronger ion binding energies than the other aminated monomers, though more studies are needed to confirm this. Both acetate and nitrate primarily detect the bare dimer, with $\left[\mathrm{N}_{2}\right]$ up to a factor of 5 higher with acetate CI than nitrate. The systematic uncertainties of the acetate measurement have similar reasons as those for $\left[\mathrm{N}_{1}\right]$ and could lead to a factor of 2-3 times lower $\left[\mathrm{N}_{2}\right]$ than reported here. These comparisons suggest that for clusters 

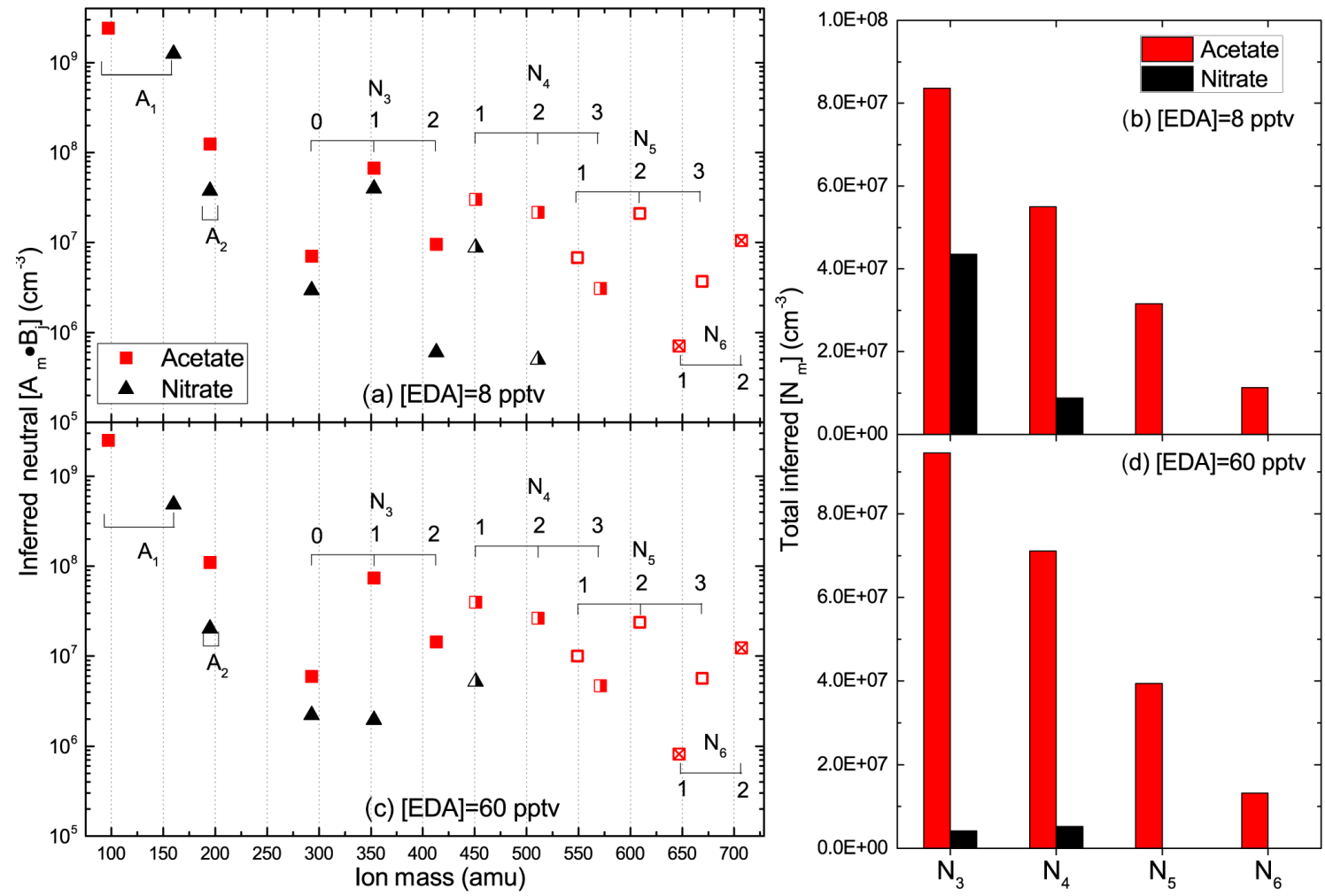

Figure 2. (a, c) Comparison of specific cluster concentrations ([ $\left.\left.\mathrm{A}_{m} \cdot \mathrm{B}_{j}\right]\right)$ using acetate (red squares) and nitrate (black triangles) reagent ions at two different $[\mathrm{EDA}]$ and a constant initial sulfuric acid concentration, $\left[\mathrm{A}_{1}\right]_{o} \sim 4 \times 10^{9} \mathrm{~cm}^{-3}$. Each cluster species is shown at its ion mass. The brackets represent the number of EDA molecules in a cluster with a given number of sulfuric acid. The half-filled symbols show the tetramers, outlined symbols as the pentamers, and crossed symbols as hexamer. Bar graphs (b) and (d) compare total cluster concentration of a given size $\left(\left[\mathrm{N}_{m}\right]\right)$ between acetate (red) and nitrate (black) for the same $[\mathrm{EDA}]$ and $\left[\mathrm{A}_{1}\right]_{o}$ as (a) and (b), respectively.

formed from diamines, nitrate does not detect as many types of $\mathrm{N}_{2}$ as does acetate; however, the large uncertainty in acetate $\left[\mathrm{N}_{2}\right]$ prevents a definitive conclusion as to whether or not nitrate chemically ionizes all types of dimers. More information is gained from experiments that vary $t_{\mathrm{CI}}$ as they are more sensitive to the various formation pathways. These results are presented in the subsequent sections.

Figures 1 through $4 \mathrm{~b}$ and d clearly show that more of the larger clusters $\left(\mathrm{N}_{3}\right.$ and higher) were detected by acetate CI than nitrate. For all bases, the $\left[\mathrm{N}_{3}\right]$ measured by acetate is 2 to 100 times higher than concentrations measured by nitrate CI. Nitrate detected small amounts of $\mathrm{N}_{4}$ and no $\mathrm{N}_{5}$, likely due to the ionizable fraction of $\left[\mathrm{N}_{4}\right]$ and $\left[\mathrm{N}_{5}\right]$ falling below detection limits $\left(<10^{5} \mathrm{~cm}^{-3}\right)$. In addition as [B] increases, the differences between acetate and nitrate cluster concentrations become more pronounced. This likely occurs because sulfuric acid clusters become more chemically neutral as [B] increases, thereby decreasing their tendencies to donate protons to nitrate ions. The differences between acetate- and nitrate-measured cluster concentrations cannot be explained only by the larger uncertainties in the acetate measurements. The systematic uncertainties in acetate-detected larger clusters is at most a factor of 2 below reported concentrations.
Thus, acetate is more efficient than nitrate at chemically ionizing the larger cluster population.

The large differences between nitrate- and acetatemeasured $\left[\mathrm{N}_{3}\right]$ and $\left[\mathrm{N}_{4}\right]$ provide information to better understand recent atmospheric and chamber measurements. Chen et al. (2012) and Jiang et al. (2011) published $\left[\mathrm{N}_{3}\right]$ and $\left[\mathrm{N}_{4}\right]$ measured in the atmosphere using a larger version of the Cluster CIMS (Zhao et al., 2010). For both studies, the measurements were conducted using nitrate $\mathrm{CI}$ and only at the clusters' bare masses $\left(A_{3}\right.$ and $\left.A_{4}\right)$. Trimers and tetramers may have been under-detected, though this is uncertain because the atmosphere contains numerous compounds that may behave differently than DMA and diamines. If the actual concentrations of trimers and tetramers were higher than those reported by Jiang et al. (2011), then the fitted evaporation rate of $E_{3}=0.4 \pm 0.3 \mathrm{~s}^{-1}$ from Chen et al. (2012) is too high and the true value would be closer to $0 \mathrm{~s}^{-1}$ (collisioncontrolled or kinetic limit) that was reported by Kürten et al. (2014) at $278 \mathrm{~K}$. In addition, Kürten et al. (2014) measured $\left[\mathrm{N}_{3}\right]$ and $\left[\mathrm{N}_{4}\right]$ about a factor of 10 lower than the collision-controlled limit. They attribute this discrepancy to decreased sensitivity to the larger ions, but it could also be due to inefficient $\mathrm{CI}$ by nitrate. 


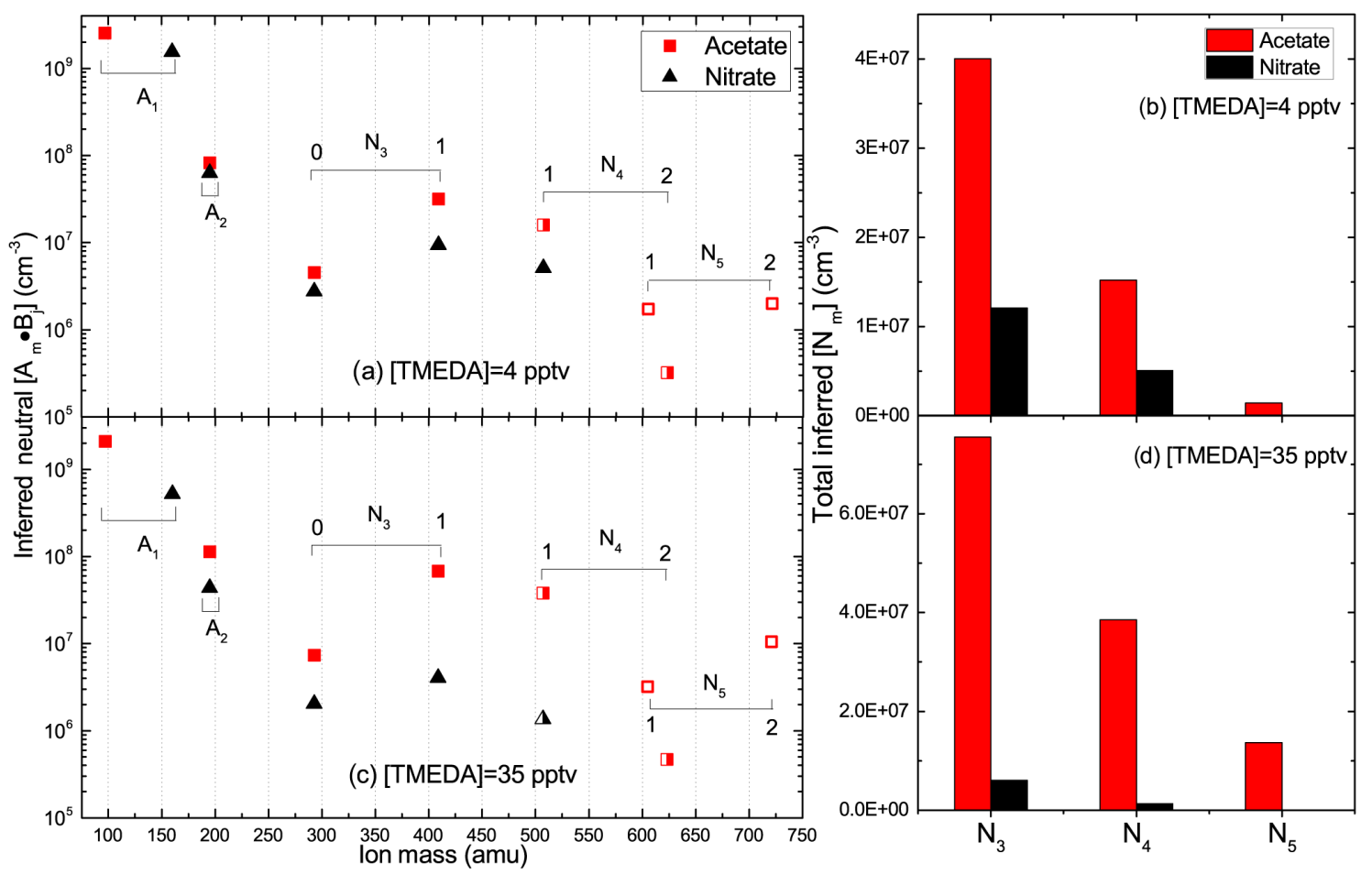

Figure 3. (a, c) Comparison of specific cluster concentrations $\left(\left[\mathrm{A}_{m} \cdot \mathrm{B}_{j}\right]\right)$ using acetate (red squares) and nitrate (black triangles) reagent ions at two different [TMEDA] and a constant initial sulfuric acid concentration, $\left[\mathrm{A}_{1}\right]_{o} \sim 4 \times 10^{9} \mathrm{~cm}^{-3}$. Each cluster species is shown at its ion mass. The brackets represent the number of TMEDA molecules in a cluster with a given number of sulfuric acid. The half-filled symbols show the tetramers and outlined symbols as the pentamers. Bar graphs (b) and (d) compare total cluster concentration of a given size ([N $\left.\left.\mathrm{N}_{m}\right]\right)$ between acetate (red) and nitrate (black) for the same [TMEDA] and $\left[\mathrm{A}_{1}\right]_{o}$ as (a) and (b), respectively.

Comparing our results to the CLOUD (Cosmics Leaving OUtdoor Droplets) experiments, the amount of clusters detected via nitrate CI using the Cluster CIMS differ from those detected by nitrate using the CI-APi-ToF (Kürten et al., 2014). They observed more ion clusters that contained nearly equal number of sulfuric acid and DMA molecules (e.g., $\mathrm{A}_{3} \cdot \mathrm{DMA}_{2}$ ). Our experiments suggest that such highly neutralized clusters are not efficiently ionized by our nitrate core ions. We do not fully understand this difference but longer acid-base reaction times, the amount of ligands on the nitrate core ions, various inlet designs (e.g., corona discharge vs. our Po-210 or high vs. our low flow rates), temperature ( $278 \mathrm{~K}$ compared to our $300 \mathrm{~K}$ ), and ion breakup upon sampling may all play a role.

Chemical ionization efficiency clearly plays a role in both the types and amounts of clusters that can be detected. However, the concentrations in Figs. 1 through 4 were calculated by assuming negligible contributions of IIC and ion decomposition. The validity of these assumptions was tested by examining the ion behavior with CI reaction time $\left(t_{\mathrm{CI}}\right)$ for a variety of bases. Presented in the following sections are ion signal variations with $t_{\mathrm{CI}}$ and a discussion of possible scenarios that explain these observations. To help understand these measurements, we developed a model to describe these com- plex series of reactions that govern neutral cluster formation, chemical ionization, IIC, and ion decomposition. The model combines two box models: one for neutral cluster formation and one for the ion processes. When compared to observations, the model was useful in identifying the controlling process for the monomers and dimers but, due to the numerous reactions, only provided general scenarios to explain observations for the larger clusters.

\section{Monomer, $\mathrm{N}_{1}$}

Over the $3 \mathrm{~s}$ neutral reaction time in this flow reactor (i.e., the reaction time between neutral sulfuric acid vapor and the basic gas), initial monomer concentration $\left(\left[\mathrm{N}_{1}\right]\right)$ is depleted as it forms larger clusters/particles and is lost to walls; $\mathrm{N}_{1}$ may reenter the gas phase by evaporation of larger clusters. Two types of $\mathrm{N}_{1}$ may have significant abundances in the sulfuric acid and DMA system: $A_{1}$ and $A_{1} \cdot$ DMA. One computational chemistry study predicts that the latter has an evaporation rate of $10^{-2} \mathrm{~s}^{-1}$ (all computed rates at $298 \mathrm{~K}$ unless otherwise stated; Ortega et al., 2012), with others suggesting an evaporation rate closer to $10 \mathrm{~s}^{-1}$ (Nadykto et al., 2014; Bork et al., 2014). 

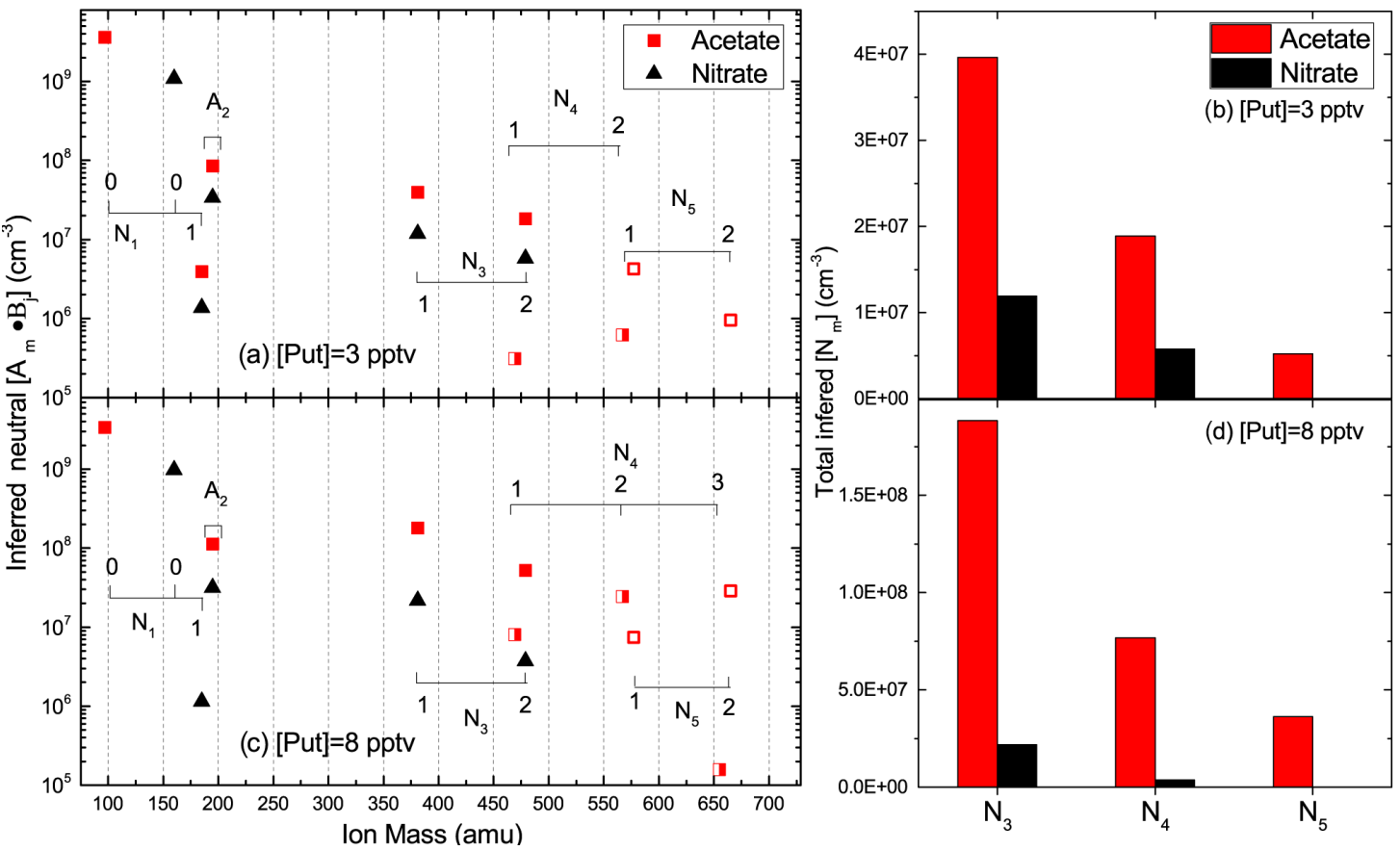

Figure 4. (a, c) Comparison of specific cluster concentrations $\left(\left[\mathrm{A}_{m} \cdot \mathrm{B}_{j}\right]\right)$ using acetate (red squares) and nitrate (black triangles) reagent ions at two different [Put] and a constant initial sulfuric acid concentration, $\left[\mathrm{A}_{1}\right]_{o} \sim 4 \times 10^{9} \mathrm{~cm}^{-3}$. Each cluster species is shown at its ion mass. The brackets represent the number of Put molecules in a cluster with a given number of sulfuric acid. The half-filled symbols show the tetramers and outlined symbols as the pentamers. Bar graphs (b) and (d) compare total cluster concentration of a given size ([N $\left.\left.\mathrm{N}_{m}\right]\right)$ between acetate (red) and nitrate (black) for the same [Put] and $\left[\mathrm{A}_{1}\right]_{o}$ as $(\mathbf{a})$ and (b), respectively.

Following the neutral clustering reactions, the remaining monomer is readily chemically ionized and the product ion can decompose and undergo IIC with the monomer or clusters. For example, the decomposition rate of $\mathrm{A}_{1}^{-} \cdot \mathrm{DMA}$ is predicted to be $10^{9} \mathrm{~s}^{-1}$ (Ortega et al., 2014). Therefore, whether or not $A_{1} \cdot$ DMA is a significant fraction of the total monomer concentration, $\mathrm{A}_{1}^{-}$is the only ion with significant abundance. This agrees with our experimental observations.

Neutral $\left[\mathrm{N}_{1}\right]$ can be estimated from mass spectrometry signals because there is negligible ion breakup in the Cluster CIMS that leads to $\mathrm{A}_{1}^{-}$. As discussed above, a number of experiments and the current results have shown this to be the case (Hanson and Eisele, 2002; Eisele and Hanson, 2000; Lovejoy and Bianco, 2000). The signal ratio of the sulfuric acid monomer at $160 \mathrm{amu}$ for nitrate $\left(S_{160}\right)$ to the nitrate ion at $125 \mathrm{amu}\left(S_{125}\right)$ can be converted to neutral [ $\left.\mathrm{N}_{1}\right]$ following Eq. (1) (Eisele and Hanson, 2000), where $t_{\mathrm{CI}}$ is the CI reaction time.

$\frac{S_{160}}{S_{125}}=k_{1}\left[\mathrm{~N}_{1}\right] t_{\mathrm{CI}}$

For $\mathrm{N}_{1}+\mathrm{HNO}_{3} \cdot \mathrm{NO}_{3}^{-}, k_{1}=1.9 \times 10^{-9} \mathrm{~cm}^{3} \mathrm{~s}^{-1}$ (Viggiano et al., 1997), which is assumed to not depend on whether water or bases are attached to the monomer. Equation (1) was derived for short $t_{\mathrm{CI}}$ where reagent ion and neutral $\mathrm{N}_{1}$ are not depleted. These assumptions are tenuous at long $t_{\mathrm{CI}}$; however, the rigorous analytical solution to the population balance equations (derived in the Supplement and given in Eq. S6) shows that Eq. (1) is a good approximation: at $t_{\mathrm{CI}}=15$ or $18 \mathrm{~ms}$, the differences between Eqs. (1) and (S6) are $\sim 1 \%$.

Figure $5 \mathrm{a}$ and $\mathrm{b}$ show the signal ratios as a function of $t_{\mathrm{CI}}$ for DMA and EDA as detected by nitrate $\mathrm{CI}$ at equivalent $\left[\mathrm{A}_{1}\right]_{o}=4 \times 10^{9} \mathrm{~cm}^{-3}$. TMEDA and Put graphs look very similar to EDA (see the Supplement). The green points shown in this figure and subsequent figures provide measurements at a base concentration of 0 pptv from eight different days and offer a useful guide for the measurement uncertainty. For all base concentrations as $t_{\mathrm{CI}}$ increases, more $\left[\mathrm{N}_{1}\right]$ is chemically ionized, leading to higher $S_{160} / S_{125}$. As $[B]$ increases, the signal ratios and therefore the slopes of the lines decrease. This indicates that $\left[\mathrm{N}_{1}\right]$ is depleted during the $3 \mathrm{~s}$ neutral reaction time via uptake into large clusters that increase with [B].

The model, as mentioned above, was used to interpret the results presented in Fig. 5 and subsequent graphs. The neutral cluster concentrations after $\left[\mathrm{A}_{1}\right]_{o}$ and $[\mathrm{B}]$ react over the $3 \mathrm{~s}$ neutral reaction time are modeled first. This portion of the model also takes into account base dilution from its injection point in the flow reactor (see Jen et al., 2014), wall loss, and particle coagulation. However, the model does not take into 


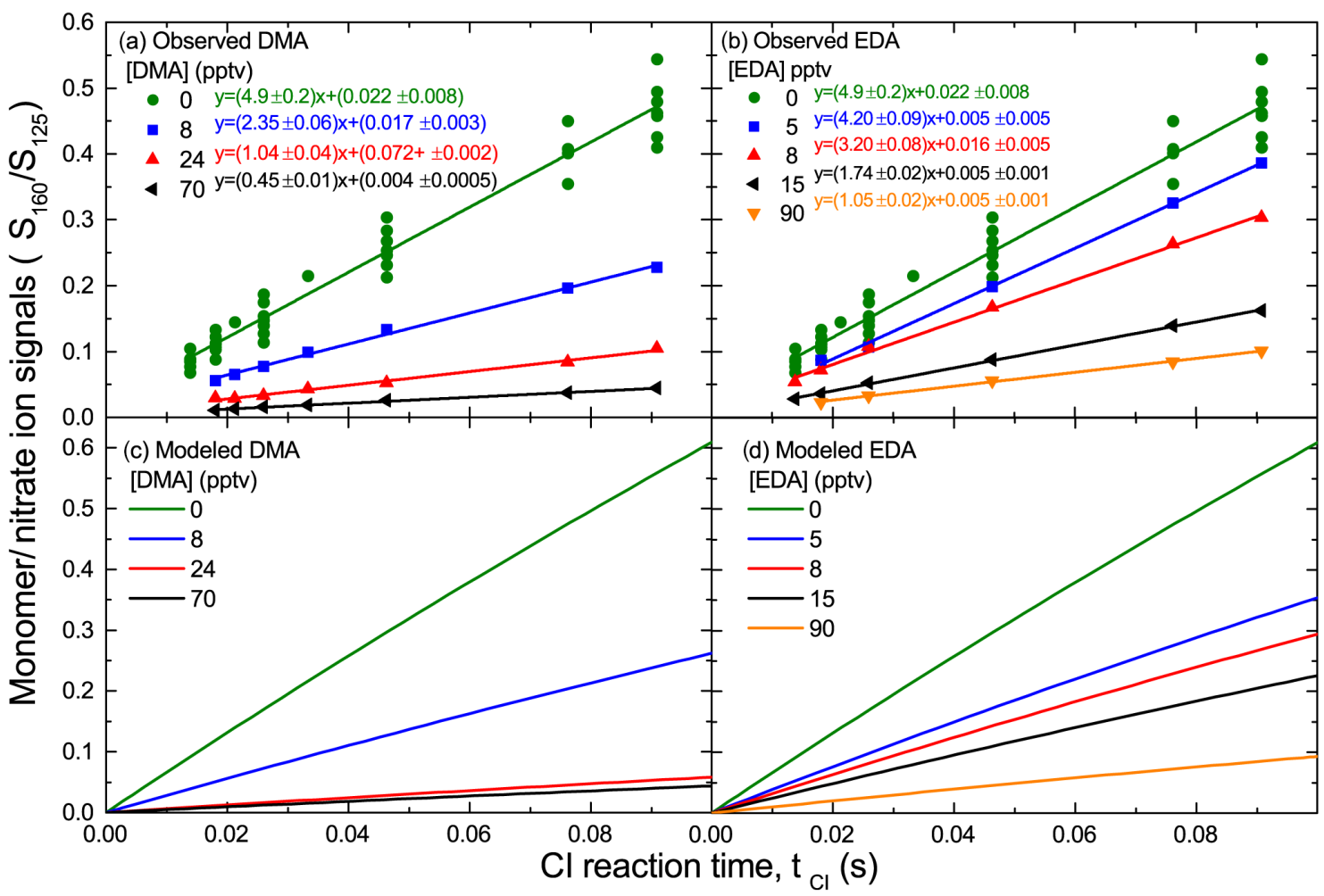

Figure 5. Measured $(\mathbf{a}, \mathbf{b})$ and modeled $(\mathbf{c}, \mathbf{d})$ sulfuric acid monomer to nitrate signal ratio $\left(S_{160} / S_{125}\right)$ as a function of CI reaction time for DMA $(\mathbf{a}, \mathbf{c})$ and EDA $(\mathbf{b}, \mathbf{d})$. The measurements were conducted with nitrate as the reagent ion and at $\left[\mathrm{A}_{1}\right]_{o} \sim 4 \times 10^{9} \mathrm{~cm}^{-3}$. Each color represents a different $[\mathrm{B}]$ with the linear regressions for the measurements given in colored text.

Table 1. Summary of possible pathways for neutral monomer formation and chemical ionization.

\begin{tabular}{ll}
\hline Neutral formation & Nitrate $\mathrm{CI}$ and ion decomposition \\
\hline DMA and diamines & DMA \\
\hline $\mathrm{A}_{1}+\mathrm{B} \leftrightarrow \mathrm{A} 1 . \mathrm{B}$ & $\mathrm{A}_{1}+\mathrm{NO}_{3}^{-} \stackrel{k_{\mathrm{c}}}{\rightarrow} \mathrm{HNO}_{3} \cdot \mathrm{A}_{1}^{-}$ \\
& $\mathrm{A}_{1} \cdot \mathrm{B}+\mathrm{NO}_{3}^{-} \stackrel{k_{\mathrm{c}}}{\rightarrow} \mathrm{HNO}_{3} \cdot \mathrm{A}_{1}^{-} \cdot \mathrm{B}$ \\
& $\mathrm{HNO}_{3} \cdot \mathrm{A}_{1}^{-} \cdot \mathrm{B} \stackrel{\text { fast }}{\rightarrow} \mathrm{HNO}_{3} \cdot \mathrm{A}_{1}^{-}+\mathrm{B}$ \\
\hline & Diamines \\
& $\mathrm{A}_{1}+\mathrm{NO}_{3}^{-} \stackrel{k_{\mathrm{c}}}{\rightarrow} \mathrm{HNO}_{3} \cdot \mathrm{A}_{1}^{-}$ \\
& $\mathrm{A}_{1} \cdot \mathrm{B}+\mathrm{NO}_{3}^{-} \stackrel{?}{\rightarrow} \mathrm{HNO}_{3} \cdot \mathrm{A}_{1}^{-} \cdot \mathrm{B}$ \\
& $\mathrm{HNO}_{3} \cdot \mathrm{A}_{1}^{-} \cdot \mathrm{B} \stackrel{\mathrm{fast}}{\rightarrow} \mathrm{HNO}_{3} \cdot \mathrm{A}_{1}^{-}+\mathrm{B}$ \\
\hline
\end{tabular}

account the possible dilution of $\mathrm{N}_{1}$ by the base addition flow, which may affect measured $\left[\mathrm{N}_{1}\right]$ as explained in the Supplement. The neutral model is then coupled to the ion model, which simulates chemical ionization and IIC. Ion decomposition is implicitly included by assuming that certain cluster types instantly decompose into the observed ion.
For the monomer, the model has identical neutral cluster formation pathways for all sulfuric acid and base systems. The acetate vs. nitrate comparison suggests that monomers containing various bases are chemically ionized similarly, with a slight possibility that nitrate may not chemically ionize sulfuric acid monomers that contain a diamine. The modeled reactions pertaining to the monomer are given in Table 1 , where $k_{\mathrm{c}}$ is $2 \times 10^{-9} \mathrm{~cm}^{3} \mathrm{~s}^{-1}$. The full list of modeled reactions, including loss of monomer to form larger clusters, is given in the Supplement.

Figure $5 \mathrm{c}$ and d display the modeled results for DMA and EDA at the same $[\mathrm{B}]$ and $\left[\mathrm{A}_{1}\right]_{o}$ as the measurements presented in panels $a$ and $b$. The model predicts the linear dependence of $S_{160} / S_{125}$ on $t_{\mathrm{CI}}$ as seen in Eq. (1). In addition, the predicted values of $S_{160} / S_{125}$ and their dependence on [B] are in good qualitative agreement with observations. Including or excluding nitrate $\mathrm{CI}$ of $\mathrm{A}_{1} \cdot$ diamine has little effect on $S_{160} / S_{125}$ because [B] is typically less than $\left[\mathrm{A}_{1}\right]_{o}$ in these experiments. As a result, the majority of monomers will remain as $\mathrm{A}_{1}$ even if the evaporation rate of the $\mathrm{A}_{1} \cdot \mathrm{B}\left(E_{1}\right)$ is very small. Further experiments that quantify the fraction of $\mathrm{A}_{1} \cdot$ diamine in $\mathrm{N}_{1}$ are needed to definitively conclude on the efficacy of nitrate in chemically ionizing all $\mathrm{N}_{1}$. 


\section{Dimer, $\mathbf{N}_{2}$}

Neutral dimers $\left(\mathrm{N}_{2}\right)$ largely form by collision of the two types of monomers $\left(\mathrm{A}_{1}\right.$ and $\left.\mathrm{A}_{1} \cdot \mathrm{B}\right)$ and, to a much lesser extent, decomposition of larger clusters. For sulfuric acid + DMA, the $\mathrm{N}_{2}$ likely exists as $\mathrm{A}_{2} \cdot \mathrm{DMA}$ and $\mathrm{A}_{2} \cdot \mathrm{DMA}_{2}$, with both clusters predicted to have low evaporation rates of $\sim 10^{-5} \mathrm{~s}^{-1}$ (Ortega et al., 2012) with another study suggesting a higher evaporation rate of $\mathrm{A}_{2} \cdot \mathrm{DMA}_{2}$ which is $\sim 10^{4}$ times higher (Leverentz et al., 2013). Chemically ionizing these dimers results in ions that undergo IIC and ion decomposition. Computational chemistry predicts that $\mathrm{A}_{2}^{-} \cdot \mathrm{DMA}_{2}$ and $\mathrm{A}_{2}^{-} \cdot \mathrm{DMA}$ have DMA evaporation rates of $10^{8}$ and $10^{2} \mathrm{~s}^{-1}$, respectively (Ortega et al., 2014). However, the computed evaporation rate of $\mathrm{A}_{2}^{-} \cdot$ DMA may be too low because during the $18 \mathrm{~ms}$ CI reaction time used here, all $\mathrm{N}_{2}$ are detected as $\mathrm{A}_{2}^{-}(195 \mathrm{amu})$. Similarly, the diamine molecule is lost from $\mathrm{A}_{2}^{-} \cdot$ diamine as all dimers were detected as $\mathrm{A}_{2}^{-}$.

$\mathrm{A}_{2}^{-}$can also be created from IIC between $\mathrm{A}_{1}^{-}$and $\mathrm{N}_{1}$ (see Reaction R2), which proceeds with a rate coefficient of $k_{21}$. Including both processes in the cluster balance equations leads to the ratio of sulfuric acid dimer (195 amu) to monomer (160 amu) signal intensities shown in Eq. (2). This relationship includes a time-independent term (the $t_{\mathrm{CI}}=0 \mathrm{~s}$ intercept) that is proportional to the neutral dimerto-monomer ratio in the sampled gas and a term due to IIC that increases linearly with $t_{\mathrm{CI}}$ (Chen et al., 2012; Hanson and Eisele, 2002).

$$
\frac{S_{195}}{S_{160}}=\frac{k_{2}}{k_{1}} \frac{\left[\mathrm{N}_{2}\right]}{\left[\mathrm{N}_{1}\right]}+\frac{1}{2} k_{21}\left[\mathrm{~N}_{1}\right] t_{\mathrm{CI}}
$$

The rate constant, $k_{21}$, is the collisional rate constant of $2 \times 10^{-9} \mathrm{~cm}^{3} \mathrm{~s}^{-1}$. Equation (2) was also derived from the assumption of short $t_{\mathrm{IC}}$. The relation for $S_{195} / S_{160} \mathrm{vs.} t_{\mathrm{CI}}$ for long $t_{\mathrm{CI}}$ is also derived in the Supplement. Equation (2) is a good approximation of the more rigorous solution even at long $t_{\mathrm{IC}}$.

Figure $6 \mathrm{a}, \mathrm{b}$, and c show measured $S_{195} / S_{160}$ as a function of $t_{\mathrm{CI}}$ for DMA, EDA, and TMEDA, respectively, as detected by nitrate $\mathrm{CI}$ at $\left[\mathrm{A}_{1}\right]_{o}=4 \times 10^{9} \mathrm{~cm}^{-3}$. Put is similar to EDA and is presented in Fig. 7 (left). For all bases, increasing the $\mathrm{CI}$ reaction time leads to more IIC dimers. The observed linear increase in the $S_{195} / S_{160}$ ratio for all bases provides evidence for the influence of IIC on dimer measurements (Eq. 2). However, the $y$ intercepts for DMA exhibit a pattern that is distinctly different from those observed for the diamines, indicating different trends for the neutralmonomer-to-dimer concentration ratios. For DMA, the $y$ intercept increases with increasing [B]. This is due to higher concentrations of base depleting the monomer and enhancing dimer concentrations. A different trend was observed for the diamines, with the intercepts showing no clear dependence on diamine concentration.
There are a number of scenarios that could partly explain the diamine trends. First, the neutral trimer evaporation rate(s) could be very low such that the formation of trimer and larger clusters will deplete both $\left[\mathrm{N}_{2}\right]$ and $\left[\mathrm{N}_{1}\right]$. The $\mathrm{A}_{1}$ evaporation rate from $A_{3} \cdot$ DMA is predicted to be $\sim 1 \mathrm{~s}^{-1}$ (Ortega et al., 2012) and likely lower for clusters with diamines (Jen et al., 2016). The second possibility is that $\mathrm{A}_{2}^{-}$ could be the decomposition product of larger ions such as $\mathrm{A}_{3}^{-} \cdot$ diamine forming $\mathrm{A}_{2}^{-}+\mathrm{A}_{1} \cdot$ diamine. A third possibility is that $\mathrm{A}_{2} \cdot$ diamine $_{2}$ cannot be readily ionized by nitrate as compared to $\mathrm{A}_{2} \cdot \mathrm{DMA}_{2}$, possibly due to differences in cluster configurations and dipole moments. As [diamine] increases, the fraction of dimers containing two diamines increases, resulting in a growing fraction of $\mathrm{N}_{2}$ that may not be ionizable by nitrate. For example, the model predicts that $\left[\mathrm{A}_{2} \cdot \mathrm{EDA}\right]$ is $10 \%$ of $\left[\mathrm{A}_{2} \cdot \mathrm{EDA}_{2}\right]$ when $[\mathrm{EDA}]=90 \mathrm{pptv}$.

The dimer $\left(S_{195}\right)$-to-monomer signal $\left(S_{97}\right)$ ratio for sulfuric acid + Put dimers measured using acetate $\mathrm{CI}$ as a function of $t_{\text {CI }}$ was examined to better understand which of these explanations is the most relevant. As mentioned previously, acetate detects the sulfuric acid monomer as $97 \mathrm{amu}$, but the detected dimer is at $195 \mathrm{amu}$ for both nitrate and acetate. Figure 7 shows the ratio of these signals for Put between nitrate (a) and acetate (c). At [Put $=40$ pptv, acetate shows a $S_{195} / S_{97} y$ intercept 25 times higher than the intercepts shown in the nitrate graph. The higher $y$ intercepts are most likely due to improved CI efficiency. A decreased detection efficiency of $97 \mathrm{amu}$ and an increased contribution due to $\mathrm{A}_{3}^{-} \cdot$ diamine decomposition due to better $\mathrm{CI}$ of $\mathrm{N}_{3}$ by acetate may also contribute (although high $\left[\mathrm{A}_{3}^{-} \cdot\right.$ diamine] in Fig. 4 suggests that these ions are stable enough during the acetate $t_{\mathrm{CI}}=15 \mathrm{~ms}$ ). More acetate results similar to Fig. $7 \mathrm{c}$ are needed to draw a more definitive conclusion, but these comparisons do suggest that dimers containing 1-2 diamines are not efficiently chemically ionized by nitrate in these experiments.

The model adds more clarity on why $\mathrm{N}_{2}$-containing diamines behave differently than DMA using nitrate CI. For DMA, the best fit to the observations was achieved by assuming all clusters can undergo nitrate ionization and can be formed by IIC. In addition, base evaporation rates from $A_{2} \cdot B_{2}$ and sulfuric acid evaporation rates from the trimer were set to $0 \mathrm{~s}^{-1}$; increasing these evaporation rates (up to 10 and $5 \mathrm{~s}^{-1}$ ) had little effect on the ratio trends. The model also assumed that $A_{3}^{-} \cdot B$ does not decompose into $A_{2}^{-}$. Figure $6 d$ shows modeling results for DMA. To reproduce $S_{195} / S_{160}$ trends of EDA and Put, the model followed that of DMA except that $\mathrm{A}_{2} \cdot \mathrm{B}_{2}$ cannot be ionized by nitrate. For TMEDA, the model also assumed that $\mathrm{A}_{2} \cdot \mathrm{TMEDA}_{2}$ does not form. Modeled results are shown in Fig. 6e and f for EDA and TMEDA, respectively, and Fig. $7 \mathrm{~b}$ for Put. The modeled pathways for $\mathrm{N}_{2}$ are listed in Table 2. For all three diamines, we were unable to reproduce the observations with other combinations of reactions and evaporation rates. The model 


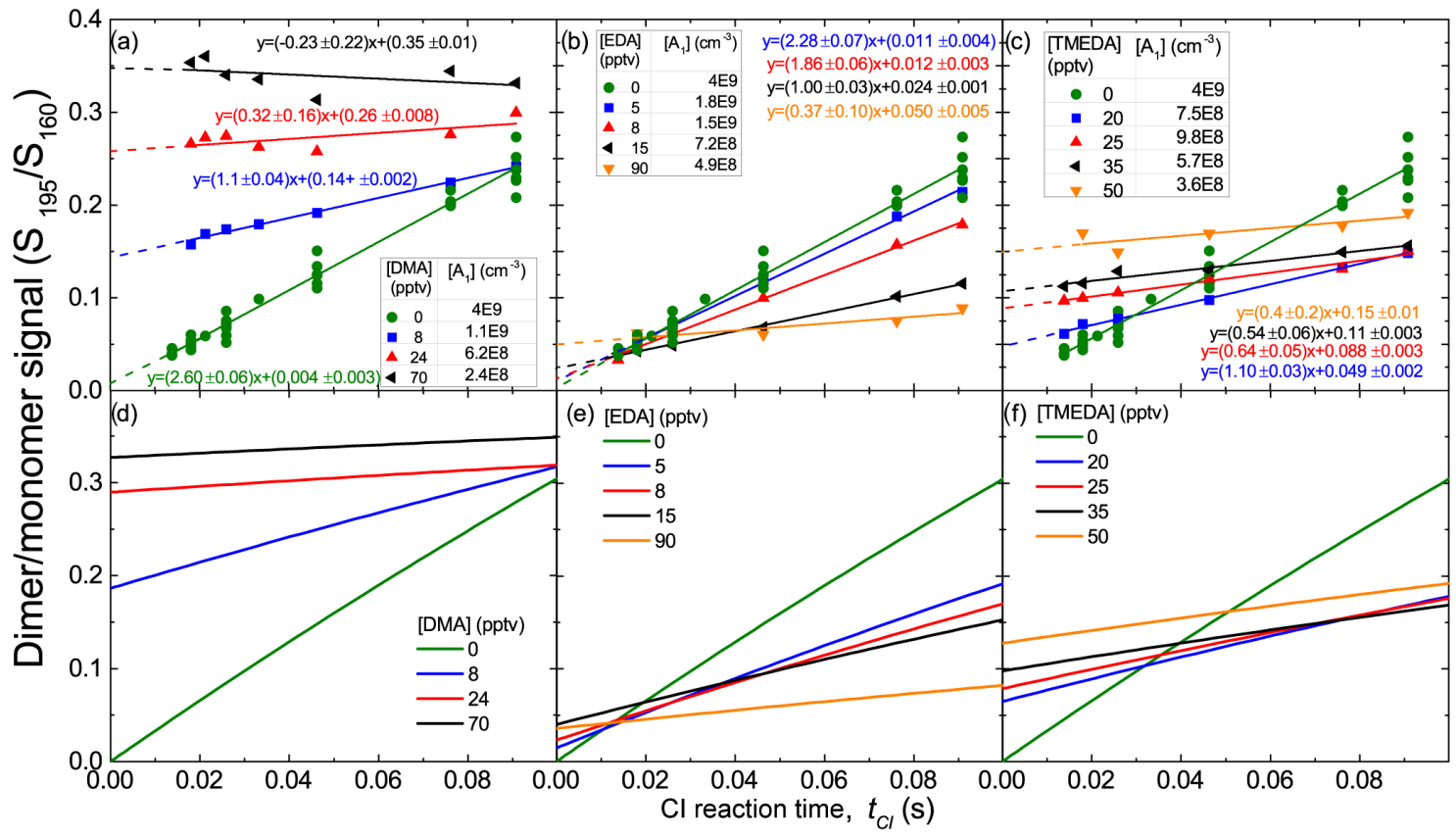

Figure 6. Measured sulfuric acid dimer to monomer signal ratio $\left(S_{195} / S_{160}\right)$ as a function of $t_{\mathrm{CI}}$ for DMA (a), EDA (b), and TMEDA (c) measured by nitrate $\mathrm{CI}$ at $\left[\mathrm{A}_{1}\right]_{o} \sim 4 \times 10^{9} \mathrm{~cm}^{-3}$. The tables in (a)-(c) provide the measured $\left[\mathrm{A}_{1}\right]$ at that $[\mathrm{B}]$ after the $3 \mathrm{~s}$ acid-base reaction time. Observations were fitted according to Eq. (2) with the $y$ intercept shown by the dashed line. Panels (d)-(f) present modeled results for each base.
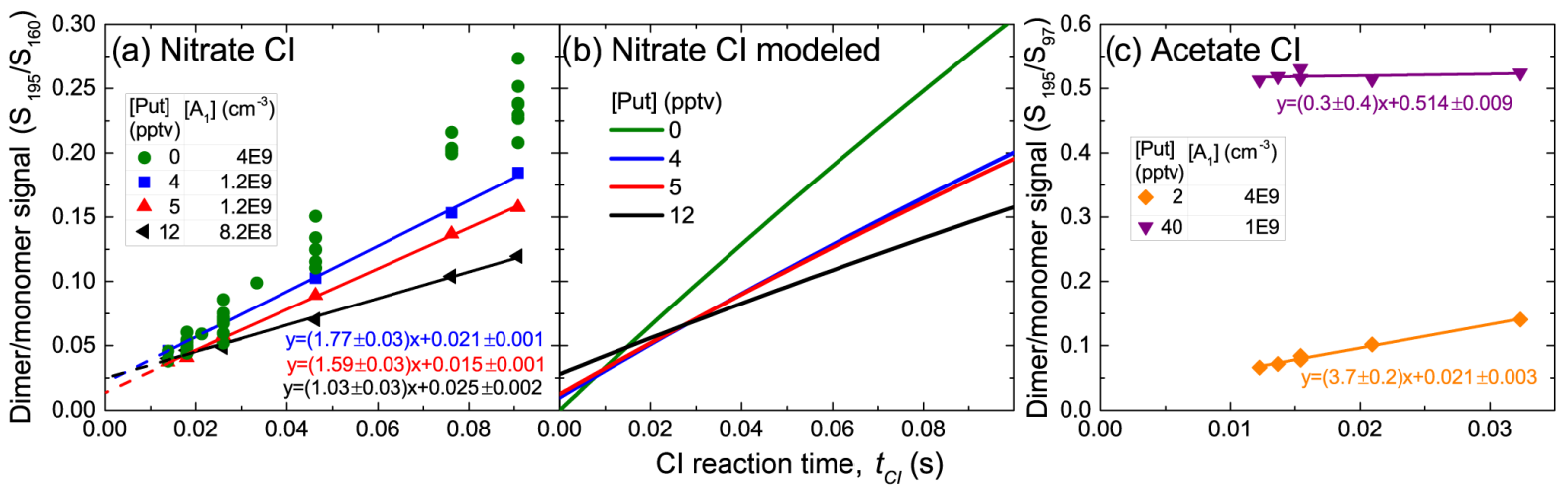

Figure 7. Measured dimer-to-monomer signal ratios $\left(S_{195} / S_{160}\right.$ for nitrate or $S_{97}$ for acetate $)$ as a function of CI reaction time using nitrate (a) and acetate $\mathrm{CI}$ (c). In both cases, $\left[\mathrm{A}_{1}\right]_{o}$ was held constant at $4 \times 10^{9} \mathrm{~cm}^{-3}$. Panel (b) shows the modeled results for Put. The tables inside (a) and (c) provide the measured $\left[\mathrm{A}_{1}\right]$ after the $3 \mathrm{~s}$ acid-base reaction time.

only matched the observed trends by turning off the CI or formation of $\mathrm{A}_{2} \cdot$ diamine $_{2}$.

However, several of the modeled reactions are simplified versions of multistep reactions. For example, preventing the formation of $\mathrm{A}_{2} \cdot \mathrm{TMEDA}_{2}$ could also mean that $\mathrm{A}_{2} \cdot \mathrm{TMEDA}_{2}$ forms at the collision rate but instantly decomposes into $A_{2}$ TMEDA. Furthermore, differences between DMA and diamine observations could instead be explained by semi-efficient nitrate $\mathrm{CI}$ of $\mathrm{A}_{2} \cdot$ diamine because the existence of high $\left[\mathrm{A}_{2} \cdot\right.$ diamine $\left._{2}\right]$ is unlikely due to its high basicity. Preventing $A_{2} \cdot$ diamine $_{2}$ from forming and semi-efficient $\mathrm{CI}$ of $\mathrm{A}_{2} \cdot$ diamine could lead to identical results as shown in the model for EDA and TMEDA. Additional thermochemical data (e.g., from more targeted experiments and computational chemistry) are needed to better inform the model. Regardless, our observations and modeling show that a dimer's neutral formation pathways and/or the nitrate CI differs between the DMA and diamine systems.

The model also provides an estimate of the fraction of $\left[\mathrm{A}_{2}^{-}\right]$formed by IIC at $t_{\mathrm{CI}}=18 \mathrm{~ms}$ (used for the nitrate CI experiments). For base concentration of 0 pptv, the model is very similar to what was measured in Fig. 6, indicating that 
Table 2. Summary of possible pathways for neutral and ion dimer formation.

\begin{tabular}{|c|c|c|}
\hline Neutral formation & Nitrate $\mathrm{CI}$ and ion decomposition reactions & IIC reactions (only $\mathrm{A}_{1}^{-}$) \\
\hline DMA, Put, EDA & DMA & All bases \\
\hline $\begin{array}{l}\mathrm{A}_{1} \cdot \mathrm{B}+\mathrm{A}_{1} \stackrel{k}{\rightarrow} \mathrm{A}_{2} \cdot \mathrm{B} \\
\mathrm{A}_{1} \cdot \mathrm{B}+\mathrm{A}_{1} \cdot \mathrm{B} \stackrel{k}{\rightarrow} \mathrm{A}_{2} \cdot \mathrm{B}_{2} \\
\mathrm{~A}_{2} \cdot \mathrm{B}+\mathrm{B} \stackrel{k}{\rightarrow} \mathrm{A}_{2} \cdot \mathrm{B}_{2} \\
\mathrm{~A}_{2} \cdot \mathrm{B}_{2} \stackrel{E_{2}}{\rightarrow} \mathrm{A}_{2} \cdot \mathrm{B}+\mathrm{B}\end{array}$ & $\begin{array}{l}\mathrm{A}_{2} \cdot \mathrm{B}+\mathrm{NO}_{3}^{-} \stackrel{k_{\mathrm{c}}}{\rightarrow} \mathrm{A}_{2}^{-} \cdot \mathrm{B}+\mathrm{HNO}_{3} \\
\mathrm{~A}_{2}^{-} \cdot \mathrm{B} \stackrel{\text { fast }}{\rightarrow} \mathrm{A}_{2}^{-}+\mathrm{B} \\
\mathrm{A}_{2} \cdot \mathrm{B}_{2}+\mathrm{NO}_{3}^{-} \stackrel{k_{\mathrm{c}}}{\rightarrow} \mathrm{A}_{2} \cdot \mathrm{B}_{2}^{-}+\mathrm{HNO}_{3} \\
\mathrm{~A}_{2}^{-} \cdot \mathrm{B}_{2} \stackrel{\text { fast }}{\rightarrow} \mathrm{A}_{2}^{-} \cdot \mathrm{B}\end{array}$ & $\begin{array}{l}\mathrm{A}_{1}^{-}+\mathrm{A}_{1} \stackrel{k_{\mathrm{c}}}{\rightarrow} \mathrm{A}_{2}^{-} \\
\mathrm{A}_{1}^{-}+\mathrm{A}_{1} \cdot \mathrm{B} \stackrel{k_{\mathrm{c}}}{\rightarrow} \mathrm{A}_{2}^{-} \cdot \mathrm{B}\end{array}$ \\
\hline TMEDA & Diamines & \\
\hline $\begin{array}{l}\mathrm{A}_{1} \cdot \mathrm{B}+\mathrm{A}_{1} \stackrel{k}{\rightarrow} \mathrm{A}_{2} \cdot \mathrm{B} \\
\mathrm{A}_{1} \cdot \mathrm{B}+\mathrm{A}_{1} \cdot \mathrm{B} \not \mathrm{A}_{2} \cdot \mathrm{B}_{2} \\
\mathrm{~A}_{2} \cdot \mathrm{B}+\mathrm{B} \Varangle \mathrm{A}_{2} \cdot \mathrm{B}_{2}\end{array}$ & $\begin{array}{l}\mathrm{A}_{2} \cdot \mathrm{B}+\mathrm{NO}_{3}^{-} \stackrel{k_{\mathrm{c}}}{\rightarrow} \mathrm{A}_{2}^{-} \cdot \mathrm{B} \\
\mathrm{A}_{2}^{-} \cdot \mathrm{B} \stackrel{\text { fast }}{\rightarrow} \mathrm{A}_{2}^{-}+\mathrm{B} \\
\mathrm{A}_{2} \cdot \mathrm{B}_{2}+\mathrm{NO}_{3}^{-} \rightarrow \mathrm{A}_{2}^{-} \cdot \mathrm{B}_{2}\end{array}$ & \\
\hline
\end{tabular}

Table 3. Summary of possible pathways for neutral and ion trimers formed from sulfuric acid and DMA, excluding decomposition of tetramer and larger ions.

\begin{tabular}{lll}
\hline Neutral formation & Nitrate $\mathrm{Cl}$ and ion decomposition reactions & IIC reactions (only $\mathrm{A}_{1}^{-}$) \\
\hline $\mathrm{A}_{2} \cdot \mathrm{B}+\mathrm{A}_{1} \stackrel{k}{\rightarrow} \mathrm{A}_{3} \cdot \mathrm{B}$ & $\mathrm{A}_{3} \cdot \mathrm{B}+\mathrm{NO}_{3}^{-} \stackrel{k_{\mathrm{c}}}{\rightarrow} \mathrm{A}_{3}^{-} \cdot \mathrm{B}+\mathrm{HNO}_{3}$ & $\mathrm{~A}_{2}^{-}+\mathrm{A}_{1} \stackrel{k_{\mathrm{c}}}{\rightarrow} \mathrm{A}_{3}^{-}$ \\
$\mathrm{A}_{3} \cdot \mathrm{B}+\mathrm{B} \stackrel{k}{\rightarrow} \mathrm{A}_{3} \cdot \mathrm{B}_{2}$ & $\mathrm{~A}_{3}^{-} \cdot \mathrm{B} \stackrel{E_{\mathrm{d}}}{\rightarrow} \mathrm{A}_{2}^{-}+\mathrm{A}_{1} \cdot \mathrm{B}$ & $\mathrm{A}_{1}^{-}+\mathrm{A}_{2} \cdot \mathrm{B} \stackrel{k_{\mathrm{c}}}{\rightarrow} \mathrm{A}_{3}^{-} \cdot \mathrm{B}$ \\
$\mathrm{A}_{3} \cdot \mathrm{B}_{2}+\mathrm{B} \stackrel{k}{\rightarrow} \mathrm{A}_{3} \cdot \mathrm{B}_{3}$ & $\mathrm{~A}_{3} \cdot \mathrm{B}_{3}+\mathrm{NO}_{3}^{-} \underset{\mathrm{A}_{3}^{-} \cdot \mathrm{B}_{3}+\mathrm{HNO}_{3}}{ }$ \\
$\mathrm{~A}_{2} \cdot \mathrm{B}_{2}+\mathrm{A}_{1} \stackrel{k}{\rightarrow} \mathrm{A}_{3} \cdot \mathrm{B}_{2}$ & $\mathrm{~A}_{3} \cdot \mathrm{B}_{2}+\mathrm{NO}_{3}^{-} \rightarrow \mathrm{A}_{3}^{-} \cdot \mathrm{B}_{2}+\mathrm{HNO}_{3}$ & \\
$\mathrm{~A}_{2} \cdot \mathrm{B}+\mathrm{A}_{1} \cdot \mathrm{B} \stackrel{k}{\rightarrow} \mathrm{A}_{3} \cdot \mathrm{B}_{2}$ & & \\
$\mathrm{~A}_{2} \cdot \mathrm{B}_{2}+\mathrm{A}_{1} \cdot \mathrm{B} \stackrel{k}{\rightarrow} \mathrm{A}_{3} \cdot \mathrm{B}_{3}$ & & \\
\hline
\end{tabular}

$\mathrm{A}_{2}^{-}$is almost completely formed by $\mathrm{A}_{1}^{-}+\mathrm{A}_{1}$ (i.e., is an IIC artifact) and not by the $\mathrm{CI}$ of $\mathrm{A}_{2}$. The abundance of $\mathrm{A}_{2}$ is low at $300 \mathrm{~K}$ (Hanson and Lovejoy, 2006), below the detection limit of the Cluster CIM. For DMA, IIC dimers typically account for $1 \%$ (less at high [DMA]) of the total dimer signal which agrees with the conclusions drawn in Jen et al. (2015). In contrast, the IIC fraction of $\mathrm{A}_{2}^{-}$using nitrate for EDA and Put is $\sim 50 \%$, due to the potentially large fraction of $\mathrm{N}_{2}$ not undergoing chemical ionization. The nitrate ion's inability to chemically ionize some of the dimers is further highlighted since IIC is suppressed in the diamine system: less $\mathrm{N}_{1}$ is available (due to the formation of larger clusters); thus, both $\left[\mathrm{A}_{1}\right]$ and $\left[\mathrm{A}_{1}^{-}\right]$are depressed. IIC-produced $\mathrm{A}_{2}^{-}$ accounts for $\sim 20 \%$ of the total dimer signal for TMEDA. However, these numbers are uncertain due to the assumptions in the model and uncertainties in the measurement. For instance, the model is not sensitive to whether $\mathrm{A}_{1}^{-}$can cluster with $A_{1} \cdot B$, which would significantly influence the amount of IIC dimer without significantly affecting $S_{195} / S_{160}$. IIC contributes much less $\mathrm{A}_{2}^{-}$when acetate is used as the reagent ion because acetate detects up to 5 times more total neutral dimer concentration $\left(\left[\mathrm{N}_{2}\right]\right)$ than nitrate when base is present. Acetate measurements show that IIC produced $\sim 3 \%$ of the
$\left[\mathrm{A}_{2}^{-}\right]$when $[\mathrm{Put}]=2 \mathrm{pptv}$ and near 0 when $[\mathrm{Put}]=40 \mathrm{pptv}$ (Fig. 7c).

\section{Trimer, $\mathrm{N}_{3}$}

Neutral trimers $\left(\mathrm{N}_{3}\right)$ are primarily formed by combining one of the two types of monomers with one of the two types of dimers; evaporation of large clusters also contributes. In the sulfuric acid+DMA system, computational chemistry predicts that $\mathrm{A}_{3} \cdot \mathrm{DMA}_{2}$ and $\mathrm{A}_{3} \cdot \mathrm{DMA}_{3}$ are relatively stable, with $\mathrm{A}_{3} \cdot \mathrm{DMA}_{3}$ exhibiting the lowest evaporation rate (Ortega et al., 2012). Also, $A_{3} \cdot$ DMA may be present in significant amounts due to a high production rate via $A_{2} \cdot D M A+A_{1}$. CI of $N_{3}$ leads to ions such as (i) $\mathrm{A}_{3}^{-} \cdot \mathrm{DMA}_{3}$, which evaporate at a rate of $10^{4} \mathrm{~s}^{-1}$ into $\mathrm{A}_{3}^{-}$. $\mathrm{DMA}_{2}$, and (ii) $\mathrm{A}_{3}^{-} \cdot \mathrm{DMA}_{2}$ and $\mathrm{A}_{3}^{-} \cdot \mathrm{DMA}$, which have predicted DMA evaporation rates of $\sim 10^{-1}$ and $10^{-2} \mathrm{~s}^{-1}$ (Ortega et al., 2014), respectively, resulting in lifetimes comparable to $t_{\mathrm{CI}}$ used here. From Fig. 1, nitrate CI resulted in $\mathrm{A}_{3}^{-} \cdot \mathrm{DMA}_{2}$ (only at $[\mathrm{DMA}]=110 \mathrm{pptv}$ ), $\mathrm{A}_{3}^{-} \cdot \mathrm{DMA}$, and $\mathrm{A}_{3}^{-}$. The DMA-containing clusters were detected to a much lesser extent than with acetate $\mathrm{CI}$. 


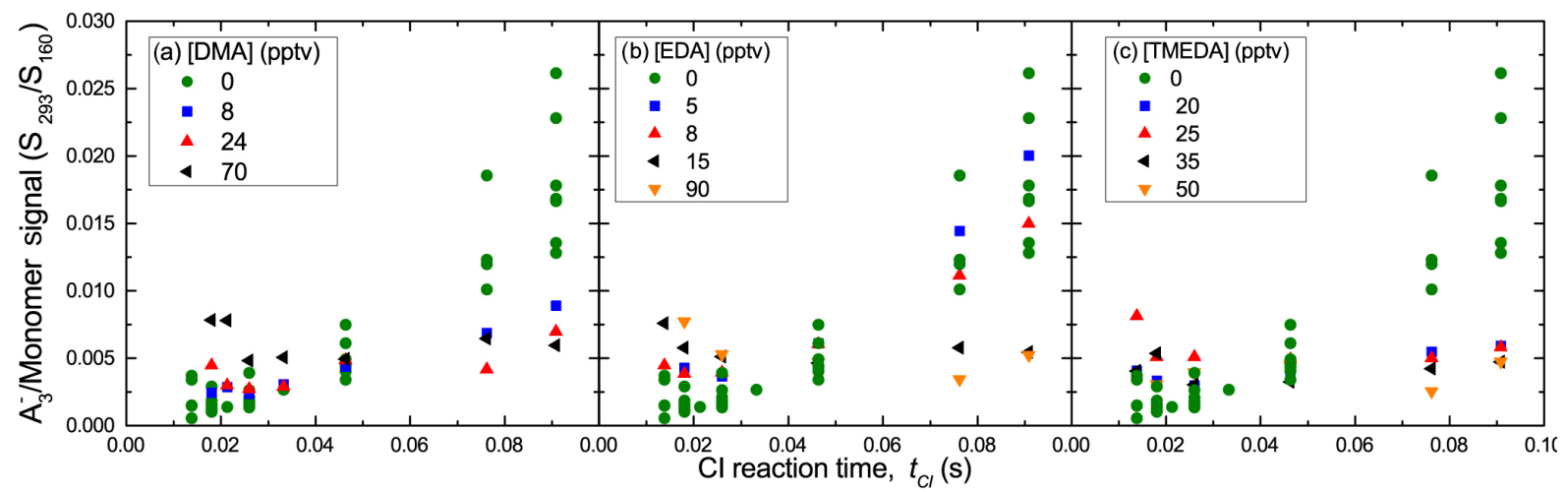

Figure 8. Measured bare sulfuric acid trimer to monomer signal ratio $\left(S_{293} / S_{160}\right)$ as a function of $t_{\mathrm{CI}}$ for DMA (a), EDA (b), and TMEDA (c) detected by nitrate CI at $\left[\mathrm{A}_{1}\right]_{o}=4 \times 10^{9} \mathrm{~cm}^{-3}$.

Acetate CI results help shed light on these processes with much higher $\left[\mathrm{A}_{3}^{-} \cdot \mathrm{DMA}_{1,2}\right]$ than with nitrate $\mathrm{CI}$ (Fig. 1), which could be due to the decomposition of larger ion clusters. The acetate CI results depicted in Fig. 1 show that $\mathrm{A}_{3}^{-} \cdot \mathrm{DMA}_{2}$ is the most abundant type of trimer ion, suggesting that the dominant neutral clusters are $\mathrm{A}_{3} \cdot \mathrm{DMA}_{2-3}$, with any $\mathrm{A}_{3}^{-} \cdot \mathrm{DMA}_{3}$ quickly decomposing into $\mathrm{A}_{3}^{-} \cdot \mathrm{DMA}_{2}$. Neutral $\mathrm{A}_{3} \cdot \mathrm{DMA}_{3}$ is predicted by our model to be dominant at high [DMA]. This picture is consistent with our postulate that nitrate cannot ionize $\mathrm{A}_{3} \cdot \mathrm{DMA}_{3}$ (and also, possibly, $\mathrm{A}_{3} \cdot \mathrm{DMA}_{2}$ ) and thus little $\mathrm{A}_{3}^{-} \cdot \mathrm{DMA}_{1,2}$ is observed using nitrate CI.

The trimer ions observed using acetate CI may have contributions from the decomposition of large clusters. For example, $\mathrm{A}_{3}^{-} \cdot \mathrm{DMA}_{2}$ could be formed by the decomposition of $\mathrm{A}_{4}^{-} \cdot \mathrm{DMA}_{2}$ or $\mathrm{A}_{4}^{-} \cdot \mathrm{DMA}_{3}$ via the loss of $\mathrm{A}_{1}$ or $\mathrm{A}_{1} \cdot \mathrm{DMA}$, respectively. If these types of processes are significant, they might explain some of the differences in the trimer ion observations between nitrate and acetate CI. Highly aminated tetramer neutrals would be more readily ionized by acetate and result in larger contributions to the trimer ion signals than compared nitrate CI. Thus, this may be one drawback to acetate CI: a possible shift downwards in sulfuric acid content in the distribution of ions vs. the neutrals.

The sulfuric acid + diamine system shows the nitrate CI detection of $\mathrm{A}_{3}^{-}$- diamine $0_{0-2}$ but at much lower abundances than acetate CI, particularly for EDA. Interestingly, the most abundant trimer ions after acetate CI contain on average one diamine molecule compared to two in the DMA system. This is consistent with particle measurements that show one diamine molecule is able to stabilize several sulfuric acid molecules and thus form a stable particle, while at least two DMA molecules are required for the same effect (Jen et al., 2016). The two amino groups on the diamine molecule can both effectively stabilize trimers, and this size is stable for the relevant timescales in this flow reactor (Glasoe et al., 2015; Jen et al., 2016). Therefore, larger clusters can be produced with higher acid-to-base ratios.
To better understand the trimer ion behaviors, we monitored the bare trimer signal $\left(\mathrm{A}_{3}^{-}, S_{293}\right)$ and monomer signal $\left(S_{160}\right)$ as a function of CI reaction time, $t_{\mathrm{CI}}$. Figure 8 shows $S_{293} / S_{160}$ for nitrate CI for DMA, EDA, and TMEDA at $\left[\mathrm{A}_{1}\right]_{o}=4 \times 10^{9} \mathrm{~cm}^{-3}$. Note that equivalent measurements for Put are similar to those of EDA. Low values of $S_{293} / S_{160}$ for all conditions indicate minimal creation of $\mathrm{A}_{3}^{-}$from the CI of $\mathrm{N}_{3}$. Thus, IIC-produced $\mathrm{A}_{3}^{-}$can be a significant fraction of observed $\mathrm{A}_{3}^{-}$. Without base present, IIC is the only way to produce detectable amounts of $\mathrm{A}_{3}^{-}$(green circles in Fig. 8).

$\mathrm{A}_{3}^{-}$can also be formed by the decomposition of larger ions such as $\mathrm{A}_{3}^{-} \cdot \mathrm{B}$. Evidence of this decomposition can be seen in Fig. 9, where $S_{\mathrm{A} 3 \cdot \mathrm{B}} / S_{160}$ measured using nitrate CI is shown as a function of $t_{\mathrm{CI}}$. For diamines at high concentrations and short $t_{\mathrm{CI}}, S_{\mathrm{A} 3 \cdot \mathrm{B}} / S_{160}$ decrease with $t_{\mathrm{CI}}$ and can be attributed to the decomposition of this ion. Shorter $t_{\mathrm{CI}}$ allows the instrument to capture short-lived ions. $\mathrm{A}_{3}^{-} \cdot$ diamine decomposes at longer times and could form $\mathrm{A}_{3}^{-}$, thereby decreasing $S_{\mathrm{A} 3 \cdot \mathrm{B}} / S_{160}$ and increasing $S_{293} / S_{160}$. However, $S_{293} / S_{160}$ for the diamines does not increase with $t_{\mathrm{CI}}$, indicating that $\mathrm{A}_{3}^{-} \cdot$ diamine likely decomposes into products other than $\mathrm{A}_{3}^{-}$. The DMA system also exhibits a very small decrease in $S_{\mathrm{A} 3 \cdot \mathrm{B}} / S_{160}$ at short $t_{\mathrm{CI}}$, but ratio values are within measurement uncertainties. Thus, no conclusion can be drawn from this decrease of $S_{\mathrm{A} 3 \cdot \mathrm{DMA}} / S_{160}$ at short $t_{\mathrm{CI}}$.

Another, more likely scenario to explain these time dependent behaviors for the trimer ion signals is if $\mathrm{A}_{3}^{-} \cdot \mathrm{B}$ decays into $\mathrm{A}_{2}^{-}$and a neutral $\mathrm{A}_{1} \cdot \mathrm{B}$ at short $t_{\mathrm{Cl}}$. Assuming we have captured most of the initial $\mathrm{A}_{3}^{-} \cdot \mathrm{B}$ signal at the shortest $t_{\mathrm{CI}}=15 \mathrm{~ms}$ in Fig. 9a-c, the increase in $\mathrm{A}_{2}^{-}$due to this mechanism would be small compared to the observed $\mathrm{A}_{2}^{-}$ signal. Acetate data for Put (Fig. 7c) provide some evidence supporting this because the slope of the $[\mathrm{Put}]=2 \mathrm{pptv}$ is 3.7 and is higher than the 2.6 slope of $[B]=0$ pptv case. Since $\mathrm{A}_{2}^{-}$when $[\mathrm{B}]=0 \mathrm{pptv}$ is primarily produced by IIC, a higher 


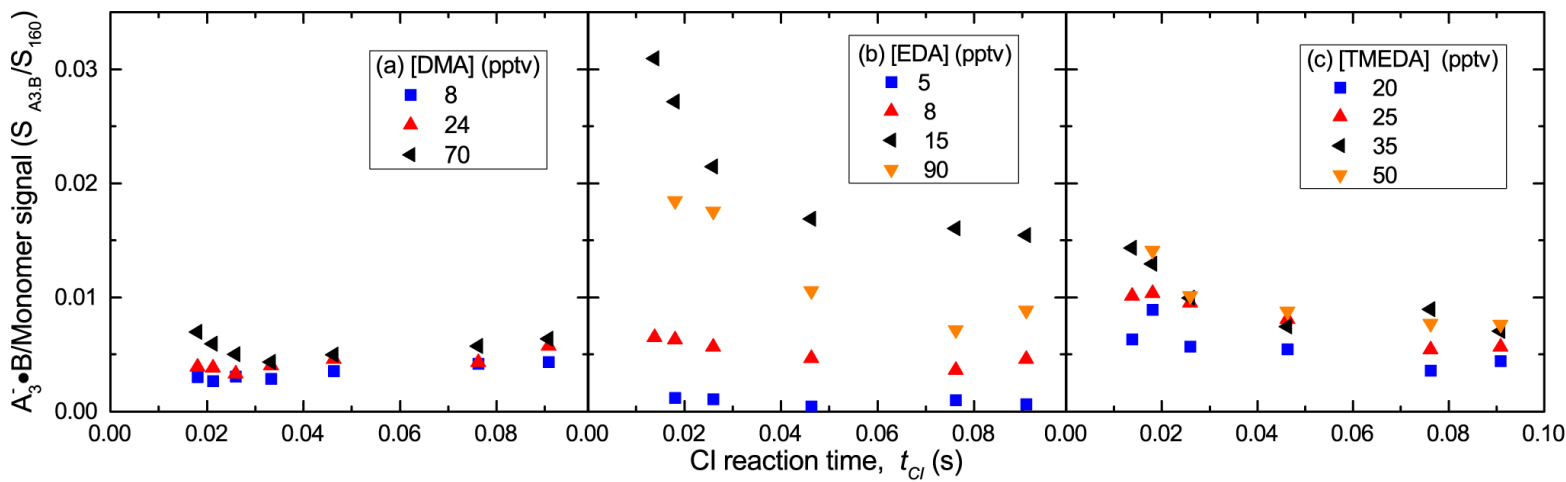

Figure 9. Nitrate-measured signal ratio between $\mathrm{A}_{3} \cdot \mathrm{B}$ and sulfuric acid monomer $\left(S_{\mathrm{A} 3} \cdot \mathrm{B} / S_{160}\right)$ as a function of $t_{\mathrm{CI}}$ for DMA (a), EDA (b), and TMEDA (c) at $\left[\mathrm{A}_{1}\right]_{o}=4 \times 10^{9} \mathrm{~cm}^{-3}$.

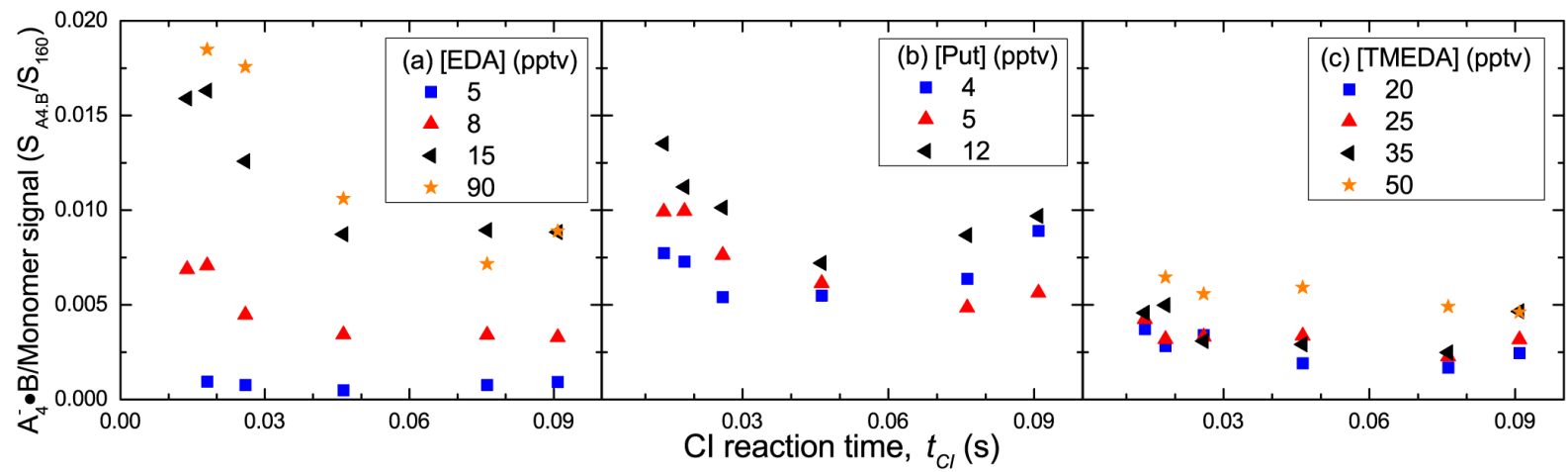

Figure 10. Nitrate-measured signal ratio between $\mathrm{A}_{4} \cdot \mathrm{B}$ and sulfuric acid monomer $\left(S_{\mathrm{A} 4 \text {.diamine }} / S_{160}\right)$ as a function of CI reaction time for EDA (a), Put (b), and TMEDA (c).

slope when $[\mathrm{Put}]=2$ pptv indicates larger ion decomposition contributing to the $\mathrm{A}_{2}^{-}$signal.

Scenarios deduced from these trimer ion observations and previous computational chemistry studies for the sulfuric acid and DMA system are summarized in Table 3. These reactions have little effect on the modeled dimer results since they introduce minor sources of dimer ions. In contrast, each trimer pathway adds large uncertainty to the modeled trimer behavior. For example, including ion decomposition reactions of larger ions (tetramer and larger), postulated from the acetate CI results, may greatly influence concentration of smaller trimer ions which already exhibit very low signals using nitrate CI. In addition, nitrate inefficient ionization of neutral trimers leads to large uncertainties in modeling the unobserved trimer types. More detailed observations of the chemically neutral trimers and computational chemistry studies on evaporation rates for sulfuric acid+diamine systems will improve future efforts to model these processes.

\section{Tetramer, $\mathbf{N}_{4}$}

Nitrate CI leads to very low amounts of tetramer ions and primarily as $\mathrm{A}_{4}^{-} \cdot \mathrm{DMA}_{1-3}$ and $\mathrm{A}_{4}^{-} \cdot$ diamine $_{1,2}$. Compu- tational chemistry suggests that the sulfuric acid+DMA tetramer likely exists as $\mathrm{A}_{4} \cdot \mathrm{DMA}_{2-4}$, with $\mathrm{A}_{4} \cdot \mathrm{DMA}_{4}$ dominating the population (Ortega et al., 2012). The acetate data appear to confirm this, with $\mathrm{A}_{4}^{-} \cdot \mathrm{DMA}_{3}$ as the most abundant tetramer ion, which likely originated predominately from the decomposition of $\mathrm{A}_{4} \cdot \mathrm{DMA}_{4}$ upon ionization (Ortega et al., 2014). Nitrate may efficiently chemically ionize $\mathrm{A}_{4} \cdot \mathrm{DMA}_{1-2}$; however, their concentrations after the $3 \mathrm{~s}$ neutral reaction time are likely below the detection limit of the Cluster CIMS $\left(<10^{5} \mathrm{~cm}^{-3}\right)$. Furthermore, the $\mathrm{A}_{4}^{-} \cdot \mathrm{DMA}_{1,2}$ ions may be subject to the elimination of $A_{1} \cdot D M A$. Nitrate $C I$ results show $\sim 100$ times higher $\left[\mathrm{A}_{4}^{-} \cdot\right.$ diamine $]$ than $\left[\mathrm{A}_{4}^{-} \cdot \mathrm{DMA}\right]$ at about equivalent initial reactant concentrations. This suggests that the most stable neutral tetramers contain fewer diamine molecules than DMA. In addition, the acetate CI results for the diamines show that the majority of $\mathrm{N}_{4}$ contain one diamine, further supporting the conclusions drawn in Jen et al. (2016) that only one diamine molecule is needed to form a stable particle.

Due to the very low observed concentration of $\mathrm{A}_{4}^{-} \cdot \mathrm{DMA}$, we focus on the ions of the diamine systems. The stability and behavior of $\mathrm{A}_{4}^{-} \cdot$ diamine can be examined by look- 
ing at nitrate-detected signal ratios of $\mathrm{A}_{4 \cdot \text { diamine }}^{-}$and the monomer $\left(S_{\mathrm{A} 4 \cdot \text { diamine }} / S_{160}\right)$ as a function of CI reaction time, given in Fig. 10. Similar to $\mathrm{A}_{3}^{-} \cdot \mathrm{EDA}, S_{\mathrm{A} 4 \cdot \mathrm{EDA}} / S_{160}$ and $S_{\mathrm{A} 4 \cdot \text { Put }} / S_{160}$ decreases with time at short $t_{\mathrm{CI}}$, indicating that they decompose with a lifetime shorter than a few tens of milliseconds. $S_{\mathrm{A} 4 \cdot \mathrm{TMEDA}} / S_{160}$ also shows a decrease at short $t_{\mathrm{CI}}$, but it is less evident. It could have a fast decay rate leading to a lifetime of a few milliseconds, and our measurements would have mostly missed them. Nonetheless, decomposition of $\mathrm{A}_{4}^{-} \cdot$ diamine likely entails the evaporation of $\mathrm{N}_{1}$ or $\mathrm{N}_{2}$ instead of a lone diamine from the cluster as $\left[\mathrm{A}_{4}^{-}\right]$was below the detection limit of the Cluster CIMS using nitrate. At long CI reaction time, $S_{\mathrm{A} 4 \cdot \mathrm{EDA}} / S_{160}$ remained constant, indicating a negligible contribution of IIC to the $\mathrm{A}_{4}^{-} \cdot \mathrm{EDA}$ signal. In contrast, $S_{\mathrm{A} 4 \cdot \mathrm{Put}} / S_{160}$ and $S_{\mathrm{A} 4 \cdot \mathrm{TMEDA}} / S_{160}$ increase at long $t_{\mathrm{CI}}$. This could be due to IIC or larger ion decomposition.

\section{Pentamer, $\mathbf{N}_{5}$}

Nitrate CI did not detect any pentamer $\left(\mathrm{N}_{5}\right)$, but pentamer was detected using acetate CI. In the diamine system, acetate detected $\mathrm{N}_{5}$ with fewer diamine molecules (12) than DMA (4). However, $A_{5}^{-} \cdot \mathrm{EDA}_{>3}, \mathrm{~A}_{5}^{-} \cdot \mathrm{TMEDA}_{>1}$, and $\mathrm{A}_{5}^{-} \cdot \mathrm{Put}_{>2}$ fall outside the Cluster CIMS mass range of $710 \mathrm{amu}$. Thus, we may not have measured the complete pentamer population. The most abundant $\mathrm{N}_{5}$ is $\mathrm{A}_{5}^{-} \cdot \mathrm{DMA}_{4}$, and it increases in both concentration and in fraction of $\mathrm{N}_{5}$ population with increasing [DMA]. This ion could be the result of the loss of a DMA molecule after CI of $\mathrm{A}_{5} \cdot \mathrm{DMA}_{5}$. This would follow similar trends predicted by computation chemistry for smaller clusters. However, since $[\mathrm{DMA}] \ll\left[\mathrm{A}_{1}\right]_{o}$ (i.e., $[\mathrm{B}] /\left[\mathrm{A}_{1}\right]_{o}$ is high) and stable particles need $\sim 2$ DMA to form (Glasoe et al., 2015), [A $A_{5} \cdot \mathrm{DMA}_{5}$ ] as high as $10^{7} \mathrm{~cm}^{-3}$ would not be expected. The presence of $\mathrm{A}_{5}^{-} \cdot \mathrm{DMA}_{4}$ could also then be the result of large ion decomposition via the evaporation of $A_{1}$ or $A_{1} \cdot D M A$. Measurements of ions larger than $700 \mathrm{amu}$ are needed to better understand how they evaporate upon acetate $\mathrm{CI}$ and what fraction of the pentamers are not ionizable by nitrate.

\section{Conclusions}

This study presents measurements of the behavior of neutral and ionized sulfuric acid clusters containing various bases. The results show the complexities of the coupled neutral cluster formation pathways with the ion processes (e.g., chemical ionization, ion-induced clustering, and ion decomposition). We provide various scenarios to describe the observed trends. Our most definitive conclusions are as follows.

1. Nitrate very likely does not chemically ionize all types of sulfuric acid dimers containing diamines. The model indicates that $\mathrm{A}_{2} \cdot$ diamine $_{2}$ cannot be chemically ion- ized by nitrate. However, the model did not consider semi-efficient nitrate $\mathrm{CI}$ of $\mathrm{A}_{2} \cdot$ diamine, which could also explain our observations.

2. Nitrate only chemically ionizes a small fraction of trimer and larger clusters in both the DMA and diamine with sulfuric acid systems. Measurements suggest that the more chemically neutral clusters are not chemically ionized by nitrate but are by acetate.

3. Acetate and nitrate CI measurements of sulfuric acid+DMA clusters generally agree with the qualitative trends of neutral and ion cluster predicted from computational chemistry (Ortega et al., 2012, 2014). However, these measurements suggest that $\mathrm{A}_{3}^{-} \cdot \mathrm{B}$ decomposes into $\mathrm{A}_{2}^{-}$and $\mathrm{A}_{1} \cdot \mathrm{B}$.

Nitrate measurements of $A_{3}^{-} \cdot B$ and $A_{4}^{-} \cdot B$ show that these ions decompose at roughly the same timescales as the $\mathrm{CI}$ reaction time at room temperature. In principle, ionization of neutral clusters leads to potentially large artifacts even before they are sampled into a vacuum system. These decomposition reactions will likely affect the calculated concentrations of the neutral clusters.

4. In an acid-rich environment where $[\mathrm{B}] /\left[\mathrm{A}_{1}\right]<1, \mathrm{~A}_{2}^{-}$ and $\mathrm{A}_{3}^{-}$are primarily produced via IIC pathways and contribute negligible amounts to overall dimer and trimer signals when any of these bases are present and at our $18 \mathrm{~ms}$ CI reaction time. If some fraction of the dimer is not chemically ionized by nitrate, then IIC-produced $\mathrm{A}_{2}^{-}$is a significant fraction of the dimer signal.

Additional computed neutral and ion evaporation rates and a more complex model combined with multivariable parameter fitting would provide more clarity to these results. In addition, more acetate CI measurements of ion signal ratios as a function of CI reaction time are needed to provide more details on specific ion behaviors. However, measurements using the acetate ion (which includes acetate, acetate $\cdot$ water, and acetic acid - acetate) exhibit high backgrounds in the low masses, leading to up to a factor of 5 uncertainty in measured monomer concentration $\left(\left[\mathrm{N}_{1}\right]\right)$ and a factor of $2-3$ for dimer concentration $\left(\left[\mathrm{N}_{2}\right]\right)$. A higher-resolution mass spectrometer is needed to resolve the background signals and reduce the uncertainties.

\section{Data availability}

All data presented in this study are available upon request from the corresponding author.

The Supplement related to this article is available online at doi:10.5194/acp-16-12513-2016-supplement. 
Author contributions. Coty N. Jen designed and performed the experiments, analyzed the results, developed the model, and prepared the paper. Jun Zhao provided useful comments on the paper. David R. Hanson helped with performing the experiments, interpreting the data, and providing comments on the paper. Peter H. McMurry assisted with data interpretation and paper preparation.

Competing interests. The authors declare that they have no conflict of interest.

Acknowledgements. Support from NSF Awards AGS1068201, AGS1338706, and AGS0943721 is gratefully acknowledged. Coty N. Jen acknowledges support from NSF GRFP award 00006595, UMN DDF, and NSF AGS Postdoctoral Fellowship award 1524211. Jun Zhao acknowledges support from SYSU 100 Talents Program.

Edited by: A. Laskin

Reviewed by: three anonymous referees

\section{References}

Almeida, J., Schobesberger, S., Kurten, A., Ortega, I. K., Kupiainen-Maatta, O., Praplan, A. P., Adamov, A., Amorim, A., Bianchi, F., Breitenlechner, M., David, A., Dommen, J., Donahue, N. M., Downard, A., Dunne, E., Duplissy, J., Ehrhart, S., Flagan, R. C., Franchin, A., Guida, R., Hakala, J., Hansel, A., Heinritzi, M., Henschel, H., Jokinen, T., Junninen, H., Kajos, M., Kangasluoma, J., Keskinen, H., Kupc, A., Kurten, T., Kvashin, A. N., Laaksonen, A., Lehtipalo, K., Leiminger, M., Leppa, J., Loukonen, V., Makhmutov, V., Mathot, S., McGrath, M. J., Nieminen, T., Olenius, T., Onnela, A., Petaja, T., Riccobono, F., Riipinen, I., Rissanen, M., Rondo, L., Ruuskanen, T., Santos, F. D., Sarnela, N., Schallhart, S., Schnitzhofer, R., Seinfeld, J. H., Simon, M., Sipila, M., Stozhkov, Y., Stratmann, F., Tome, A., Trostl, J., Tsagkogeorgas, G., Vaattovaara, P., Viisanen, Y., Virtanen, A., Vrtala, A., Wagner, P. E., Weingartner, E., Wex, H., Williamson, C., Wimmer, D., Ye, P., Yli-Juuti, T., Carslaw, K. S., Kulmala, M., Curtius, J., Baltensperger, U., Worsnop, D. R., Vehkamaki, H., and Kirkby, J.: Molecular understanding of sulphuric acid-amine particle nucleation in the atmosphere, Nature, 502, 359-363, doi:10.1038/nature12663, 2013.

Ball, S. M., Hanson, D. R., Eisele, F. L., and McMurry, P. H.: Laboratory studies of particle nucleation: Initial results for $\mathrm{H}_{2} \mathrm{SO}_{4}$, $\mathrm{H}_{2} \mathrm{O}$, and $\mathrm{NH}_{3}$ vapors, J. Geophys. Res.-Atmos., 104, 23709 23718, doi:10.1029/1999JD900411, 1999.

Berresheim, H., Elste, T., Plass-Dülmer, C., Eisele, F. L., and Tanner, D. J.: Chemical ionization mass spectrometer for long-term measurements of atmospheric $\mathrm{OH}$ and $\mathrm{H}_{2} \mathrm{SO}_{4}$, Int. J. Mass Spectrom., 202, 91-109, doi:10.1016/s1387-3806(00)00233-5, 2000.

Bork, N., Elm, J., Olenius, T., and Vehkamäki, H.: Methane sulfonic acid-enhanced formation of molecular clusters of sulfuric acid and dimethyl amine, Atmos. Chem. Phys., 14, 12023 12030, doi:10.5194/acp-14-12023-2014, 2014.
Chen, M., Titcombe, M., Jiang, J., Jen, C., Kuang, C., Fischer, M. L., Eisele, F. L., Siepmann, J. I., Hanson, D. R., Zhao, J., and McMurry, P. H.: Acid-base chemical reaction model for nucleation rates in the polluted atmospheric boundary layer, P. Natl. Acad. Sci. USA, 109, 18713-18718, doi:10.1073/pnas.1210285109, 2012.

Coffman, D. J. and Hegg, D. A.: A preliminary study of the effect of ammonia on particle nucleation in the marine boundary layer, J. Geophys. Res.-Atmos., 100, 7147-7160, doi:10.1029/94JD03253, 1995.

Eisele, F. L. and Hanson, D. R.: First Measurement of Prenucleation Molecular Clusters, J. Phys. Chem. A, 104, 830-836, doi:10.1021/jp9930651, 2000.

Elm, J., Jen, C. N., Kurtén, T., and Vehkamäki, H.: Strong Hydrogen Bonded Molecular Interactions between Atmospheric Diamines and Sulfuric Acid, J. Phys. Chem. A, 120, 3693-3700, doi:10.1021/acs.jpca.6b03192, 2016.

Freshour, N. A., Carlson, K. K., Melka, Y. A., Hinz, S., Panta, B., and Hanson, D. R.: Amine permeation sources characterized with acid neutralization and sensitivities of an amine mass spectrometer, Atmos. Meas. Tech., 7, 3611-3621, doi:10.5194/amt7-3611-2014, 2014.

Glasoe, W. A., Volz, K., Panta, B., Freshour, N., Bachman, R., Hanson, D. R., McMurry, P. H., and Jen, C.: Sulfuric Acid Nucleation: An Experimental Study of the Effect of Seven Bases, J. Geophys. Res.-Atmos., 1933-1950, doi:10.1002/2014JD022730, 2015.

Hanson, D. R. and Eisele, F. L.: Measurement of prenucleation molecular clusters in the $\mathrm{NH}_{3}, \mathrm{H}_{2} \mathrm{SO}_{4}, \mathrm{H}_{2} \mathrm{O}$ system, J. Geophys. Res., 107, AAC 10-11-AAC 10-18, doi:10.1029/2001jd001100, 2002.

Hanson, D. R. and Lovejoy, E. R.: Measurement of the Thermodynamics of the Hydrated Dimer and Trimer of Sulfuric Acid, J. Phys. Chem. A, 110, 9525-9528, doi:10.1021/jp062844w, 2006.

IPCC: Climate Change 2014: Impacts, Adaptation, and Vulnerability, Part A: Global and Sectoral Aspects, in: Contribution of Working Group II to the Fifth Assessment Report of the Intergovernmental Panel on Climate Change, edited by: Field, C. B., Barros, V. R., Dokken, D. J., Mach, K. J., Mastrandrea, M. D., Bilir, T. E., Chatterjee, M., Ebi, K. L., Estrada, Y. O., Genova, R. C., Girma, B., Kissel, E. S., Levy, A. N., MacCracken, S., Mastrandrea, and White, L. L., Cambridge University Press, Cambridge, United Kingdom and New York, NY, USA, 1132 pp., 2014.

Jen, C. N., McMurry, P. H., and Hanson, D. R.: Stabilization of sulfuric acid dimers by ammonia, methylamine, dimethylamine, and trimethylamine, J. Geophys. Res.-Atmos., 119, 7502-7514, doi:10.1002/2014JD021592, 2014.

Jen, C. N., Hanson, D. R., and McMurry, P. H.: Towards Reconciling Measurements of Atmospherically Relevant Clusters by Chemical Ionization Mass Spectrometry and Mobility Classification/Vapor Condensation, Aerosol Sci. Technol., ARL, 49, i-iii, doi:10.1080/02786826.2014.1002602, 2015.

Jen, C. N., Bachman, R., Zhao, J., McMurry, P. H., and Hanson, D. R.: Diamine-sulfuric acid reactions are a potent source of new particle formation, Geophys. Res. Lett., 43, 867-873, doi:10.1002/2015GL066958, 2016.

Jiang, J., Zhao, J., Chen, M., Eisele, F. L., Scheckman, J., Williams, B. J., Kuang, C., and McMurry, P. H.: First Measurements of Neutral Atmospheric Cluster and 1-2 nm Particle Number Size 
Distributions During Nucleation Events, Aerosol Sci. Technol., 45, ii-v, doi:10.1080/02786826.2010.546817, 2011.

Jokinen, T., Sipilä, M., Junninen, H., Ehn, M., Lönn, G., Hakala, J., Petäjä, T., Mauldin III, R. L., Kulmala, M., and Worsnop, D. R.: Atmospheric sulphuric acid and neutral cluster measurements using CI-APi-TOF, Atmos. Chem. Phys., 12, 4117-4125, doi:10.5194/acp-12-4117-2012, 2012.

Kirkby, J., Curtius, J., Almeida, J., Dunne, E., Duplissy, J., Ehrhart, S., Franchin, A., Gagne, S., Ickes, L., Kurten, A., Kupc, A., Metzger, A., Riccobono, F., Rondo, L., Schobesberger, S., Tsagkogeorgas, G., Wimmer, D., Amorim, A., Bianchi, F., Breitenlechner, M., David, A., Dommen, J., Downard, A., Ehn, M., Flagan, R. C., Haider, S., Hansel, A., Hauser, D., Jud, W., Junninen, H., Kreissl, F., Kvashin, A., Laaksonen, A., Lehtipalo, K., Lima, J., Lovejoy, E. R., Makhmutov, V., Mathot, S., Mikkila, J., Minginette, P., Mogo, S., Nieminen, T., Onnela, A., Pereira, P., Petaja, T., Schnitzhofer, R., Seinfeld, J. H., Sipila, M., Stozhkov, Y., Stratmann, F., Tome, A., Vanhanen, J., Viisanen, Y., Vrtala, A., Wagner, P. E., Walther, H., Weingartner, E., Wex, H., Winkler, P. M., Carslaw, K. S., Worsnop, D. R., Baltensperger, U., and Kulmala, M.: Role of sulphuric acid, ammonia and galactic cosmic rays in atmospheric aerosol nucleation, Nature, 476, 429-433, doi:10.1038/nature10343, 2011.

Kuang, C., McMurry, P. H., McCormick, A. V., and Eisele, F. L.: Dependence of nucleation rates on sulfuric acid vapor concentration in diverse atmospheric locations, J. Geophys. Res.-Atmos., 113, D10209, doi:10.1029/2007jd009253, 2008.

Kulmala, M., Vehkamäki, H., Petäjä, T., Dal Maso, M., Lauri, A., Kerminen, V. M., Birmili, W., and McMurry, P. H.: Formation and growth rates of ultrafine atmospheric particles: a review of observations, J. Aerosol Sci., 35, 143-176, doi:10.1016/j.jaerosci.2003.10.003, 2004.

Kürten, A., Jokinen, T., Simon, M., Sipilä, M., Sarnela, N., Junninen, H., Adamov, A., Almeida, J., Amorim, A., Bianchi, F., Breitenlechner, M., Dommen, J., Donahue, N. M., Duplissy, J., Ehrhart, S., Flagan, R. C., Franchin, A., Hakala, J., Hansel, A., Heinritzi, M., Hutterli, M., Kangasluoma, J., Kirkby, J., Laaksonen, A., Lehtipalo, K., Leiminger, M., Makhmutov, V., Mathot, S., Onnela, A., Petäjä, T., Praplan, A. P., Riccobono, F., Rissanen, M. P., Rondo, L., Schobesberger, S., Seinfeld, J. H., Steiner, G., Tomé, A., Tröstl, J., Winkler, P. M., Williamson, C., Wimmer, D., Ye, P., Baltensperger, U., Carslaw, K. S., Kulmala, M., Worsnop, D. R., and Curtius, J.: Neutral molecular cluster formation of sulfuric acid-dimethylamine observed in real time under atmospheric conditions, P. Natl. Acad. Sci. USA, 111, 1501915024, doi:10.1073/pnas.1404853111, 2014.

Kurtén, T., Petäjä, T., Smith, J., Ortega, I. K., Sipilä, M., Junninen, H., Ehn, M., Vehkamäki, H., Mauldin, L., Worsnop, D. R., and Kulmala, M.: The effect of $\mathrm{H}_{2} \mathrm{SO}_{4}$ - amine clustering on chemical ionization mass spectrometry (CIMS) measurements of gas-phase sulfuric acid, Atmos. Chem. Phys., 11, 3007-3019, doi:10.5194/acp-11-3007-2011, 2011

Leopold, K. R.: Hydrated Acid Clusters, Annu. Rev. Phys. Chem., 62, 327-349, doi:10.1146/annurev-physchem-032210-103409, 2011.

Leverentz, H. R., Siepmann, J. I., Truhlar, D. G., Loukonen, V., and Vehkamäki, H.: Energetics of Atmospherically Implicated Clusters Made of Sulfuric Acid, Ammonia, and Dimethyl Amine, J. Phys. Chem. A, 117, 3819-3825, doi:10.1021/jp402346u, 2013.
Lovejoy, E. R. and Bianco, R.: Temperature Dependence of Cluster Ion Decomposition in a Quadrupole Ion Trap, J. Phys. Chem. A, 104, 10280-10287, doi:10.1021/jp001216q, 2000.

Lovejoy, E. R. and Curtius, J.: Cluster Ion Thermal Decomposition (II): Master Equation Modeling in the Low-Pressure Limit and Fall-Off Regions, Bond Energies for $\mathrm{HSO}_{4}-\left(\mathrm{H}_{2} \mathrm{SO}_{4}\right)_{x}\left(\mathrm{HNO}_{3}\right)_{y}$, J. Phys. Chem. A, 105, 10874-10883, doi:10.1021/jp012496s, 2001.

McGrath, M. J., Olenius, T., Ortega, I. K., Loukonen, V., Paasonen, P., Kurtén, T., Kulmala, M., and Vehkamäki, H.: Atmospheric Cluster Dynamics Code: a flexible method for solution of the birth-death equations, Atmos. Chem. Phys., 12, 2345-2355, doi:10.5194/acp-12-2345-2012, 2012.

Nadykto, A. B., Herb, J., Yu, F., and Xu, Y.: Enhancement in the production of nucleating clusters due to dimethylamine and large uncertainties in the thermochemistry of amine-enhanced nucleation, Chem. Phys. Lett., 609, 42-49, doi:10.1016/j.cplett.2014.03.036, 2014.

Ortega, I. K., Kupiainen, O., Kurtén, T., Olenius, T., Wilkman, O., McGrath, M. J., Loukonen, V., and Vehkamäki, H.: From quantum chemical formation free energies to evaporation rates, Atmos. Chem. Phys., 12, 225-235, doi:10.5194/acp-12-225-2012, 2012.

Ortega, I. K., Olenius, T., Kupiainen-Määttä, O., Loukonen, V., Kurtén, T., and Vehkamäki, H.: Electrical charging changes the composition of sulfuric acid-ammonia/dimethylamine clusters, Atmos. Chem. Phys., 14, 7995-8007, doi:10.5194/acp-14-79952014, 2014.

Riipinen, I., Sihto, S.-L., Kulmala, M., Arnold, F., Dal Maso, M., Birmili, W., Saarnio, K., Teinilä, K., Kerminen, V.-M., Laaksonen, A., and Lehtinen, K. E. J.: Connections between atmospheric sulphuric acid and new particle formation during QUEST III-IV campaigns in Heidelberg and Hyytiälä, Atmos. Chem. Phys., 7, 1899-1914, doi:10.5194/acp-7-1899-2007, 2007.

Schobesberger, S., Junninen, H., Bianchi, F., Lönn, G., Ehn, M., Lehtipalo, K., Dommen, J., Ehrhart, S., Ortega, I. K., Franchin, A., Nieminen, T., Riccobono, F., Hutterli, M., Duplissy, J., Almeida, J., Amorim, A., Breitenlechner, M., Downard, A. J., Dunne, E. M., Flagan, R. C., Kajos, M., Keskinen, H., Kirkby, J., Kupc, A., Kürten, A., Kurtén, T., Laaksonen, A., Mathot S., Onnela, A., Praplan, A. P., Rondo, L., Santos, F. D., Schallhart, S., Schnitzhofer, R., Sipilä, M., Tomé, A., Tsagkogeorgas, G., Vehkamäki, H., Wimmer, D., Baltensperger, U., Carslaw, K. S., Curtius, J., Hansel, A., Petäjä, T., Kulmala, M., Donahue, N. M., and Worsnop, D. R.: Molecular understanding of atmospheric particle formation from sulfuric acid and large oxidized organic molecules, P. Natl. Acad. Sci. USA, 110, 17223-17228, doi:10.1073/pnas.1306973110, 2013.

$\mathrm{Su}, \mathrm{T}$. and Bowers, M. T.: Theory of ion-polar molecule collisions, Comparison with experimental charge transfer reactions of rare gas ions to geometric isomers of difluorobenzene and dichloroethylene, J. Chem. Phys., 58, 3027-3037, doi:10.1063/1.1679615, 1973.

Veres, P., Roberts, J. M., Warneke, C., Welsh-Bon, D., Zahniser, M., Herndon, S., Fall, R., and de Gouw, J.: Development of negative-ion proton-transfer chemical-ionization mass spectrometry (NI-PT-CIMS) for the measurement of gas-phase organic acids in the atmosphere, Int. J. Mass Spectrom., 274, 48-55, doi:10.1016/j.ijms.2008.04.032, 2008. 
Viggiano, A. A., Seeley, J. V., Mundis, P. L., Williamson, J. S., and Morris, R. A.: Rate Constants for the Reactions of $\mathrm{XO}_{3}^{-}\left(\mathrm{H}_{2} \mathrm{O}\right)_{n}$ $(X=\mathrm{C}, \mathrm{HC}$, and $\mathrm{N})$ and $\mathrm{NO}_{3}^{-}\left(\mathrm{HNO}_{3}\right)_{n}$ with $\mathrm{H}_{2} \mathrm{SO}_{4}$ : Implications for Atmospheric Detection of $\mathrm{H}_{2} \mathrm{SO}_{4}$, J. Phys. Chem. A, 101, 8275-8278, doi:10.1021/jp971768h, 1997.

Weber, R. J., Marti, J. J., McMurry, P. H., Eisele, F. L., Tanner, D. J., and Jefferson, A.: Measured atmospheric new particle formation rates: implications for nucleation mechanisms, Chem. Eng. Commun., 151, 53-64, doi:10.1080/00986449608936541, 1996.

Zhao, J., Eisele, F. L., Titcombe, M., Kuang, C., and McMurry, P. $\mathrm{H}$.: Chemical ionization mass spectrometric measurements of atmospheric neutral clusters using the cluster-CIMS, J. Geophys. Res., 115, D08205, doi:10.1029/2009jd012606, 2010.
Zhao, J., Smith, J. N., Eisele, F. L., Chen, M., Kuang, C., and McMurry, P. H.: Observation of neutral sulfuric acid-amine containing clusters in laboratory and ambient measurements, Atmos. Chem. Phys., 11, 10823-10836, doi:10.5194/acp-1110823-2011, 2011.

Zollner, J. H., Glasoe, W. A., Panta, B., Carlson, K. K., McMurry, P. H., and Hanson, D. R.: Sulfuric acid nucleation: power dependencies, variation with relative humidity, and effect of bases, Atmos. Chem. Phys., 12, 4399-4411, doi:10.5194/acp-12-43992012, 2012. 